\title{
Experimental Research on Quick Structural Health Monitoring Technique for Bridges Using Smartphone
}

\author{
Xuefeng Zhao, ${ }^{1,2,3}$ Kwang Ri, ${ }^{1,2,3,4}$ Ruicong Han, ${ }^{1,2,3}$ Yan Yu, \\ Mingchu $\mathrm{Li}^{6}{ }^{6}$ and Jinping $\mathrm{Ou}^{1,2,3,7}$ \\ ${ }^{1}$ School of Civil Engineering, Dalian University of Technology, Dalian 116024, China \\ ${ }^{2}$ State Key Laboratory of Coastal and Offshore Engineering, Dalian University of Technology, Dalian 116024, China \\ ${ }^{3}$ Research Center of Structural Smartphone Cloud Monitoring, Dalian University of Technology, Dalian 116024, China \\ ${ }^{4}$ School of Civil Engineering, Pyongyang University of Architecture, Pyongyang 1001, Democratic People's Republic of Korea \\ ${ }^{5}$ School of Electronic Science and Technique, Dalian University of Technology, Dalian 116000, China \\ ${ }^{6}$ School of Software Technology, Dalian University of Technology, Dalian 116000, China \\ ${ }^{7}$ School of Civil Engineering, Harbin Institute of Technology, Harbin 150000, China \\ Correspondence should be addressed to Xuefeng Zhao; zhaoxf@dlut.edu.cn
}

Received 19 May 2016; Accepted 25 September 2016

Academic Editor: Chunhui Yang

Copyright (C) 2016 Xuefeng Zhao et al. This is an open access article distributed under the Creative Commons Attribution License, which permits unrestricted use, distribution, and reproduction in any medium, provided the original work is properly cited.

In the recent years, with the development and popularization of smartphone, the utilization of smartphone in the Structural Health Monitoring (SHM) has attracted increasing attention owing to its unique feature. Since bridges are of great importance to society and economy, bridge health monitoring has very practical significance during its service life. Furthermore, rapid damage assessment of bridge after an extreme event such as earthquake is very important in the recovery work. Smartphone-based bridge health monitoring and postevent damage evaluation have advantages over the conventional monitoring techniques, such as low cost, ease of installation, and convenience. Therefore, this study investigates the implementation feasibility of the quick bridge health monitoring technique using smartphone. A novel vision-based cable force measurement method using smartphone camera is proposed, and, then, its feasibility and practicality is initially validated through cable model test. An experiment regarding multiple parameters monitoring of one bridge scale model is carried out. Parameters, such as acceleration, displacement, and angle, are monitored using smartphone. The experiment results show that there is a good agreement between the reference sensor and smartphone measurements in both time and frequency domains.

\section{Introduction}

With the advances in sensor and computer technologies in the recent years, Structural Health Monitoring (SHM) has developed rapidly and has become a major research field in civil engineering, which provides a useful diagnostic tool for ensuring integrity and safety, detecting damage, and evaluating performance deterioration of civil infrastructures [1-3]. SHM systems have undergone significant development and been widely utilized on infrastructures, especially bridge structures $[4,5]$. Present SHM systems have been mainly installed on some of large-scale structures or major construction projects with great significance [6], such as long-span bridges, due to the financial problems and practical difficulties associated with instrumentation and monitoring.

Generally, there is possibility for the civil structures to be subjected to severe loadings during their service life owing to extreme disaster such as earthquake and typhoon, which causes serious damage to the integrity of the structures. When an extreme disaster occurs, the rapid damage detection of bridges will be helpful for the quick evaluation of transportation networks for the emergency response [7]. Although the SHM system installed on bridge provides realtime information for damage assessment after a disaster, not all bridges have been installed with the SHM system. Furthermore, the installed SHM systems can be easily destroyed in the disaster. Therefore, it is necessary to develop quick 
SHM technique for rapid structure response monitoring and safety assessment, which will provide preliminary damage evaluation result before time-consuming common inspection can be conducted. The rapid SHM technique based on ubiquitous smartphone with built-in sensors would make it possible for personnel to evaluate initial damage and safety status quickly, because of its features such as low cost, ease of installation, and convenience.

Several researchers studied the monitoring ability of smartphones through laboratory and field tests and confirmed the potential usage of smartphones in the health monitoring of civil infrastructures. Yu et al. [8] proposed a new idea for mobile SHM using smartphone built-in sensors or external sensors board for the first time, carried out preliminary test to validate its feasibility and implementation, and then mentioned that mobile SHM system based on public participant under emergency condition is possible because of its features such as low cost and popularization. Morgenthal and Höpfner [9] investigated the effect of sampling rate on acceleration measurement. Android device (version 2.3) recorded acceleration data of shaking table with a sampling rate of $27 \mathrm{~Hz}$ under excitations of different frequencies. It was found that the vibration responses could not be accurately obtained for measuring vibration above Nyquist frequency of smartphone built-in accelerometer. Reilly et al. [10] developed a mobile application iShake using smartphones as seismologic sensors, which is possible for smartphones to measure and transmit ground motion data to a central server, and validated the accuracy of smartphone built-in sensors for seismic sensing application through shaking table tests. Sharma and Gupta [11] studied the use of smartphone in civil engineering and measured various field parameters including absolute location, distance, area, and perimeter using smartphone GPS receiver and also evaluated noise pollution using microphone of smartphone. Cimellaro et al. [12] developed multiple platforms including smartphones and Internet for rapid building damage assessment after a seismic event, which collected photos of damaged houses taken by residents or volunteers in damaged area as the first emergency response information. Han et al. [13] measured cable force of cablestayed bridge with accelerometer embedded in smartphone, which showed that it is appropriate to estimate the cable force from smartphone inner sensors limited in precision of measurement because cable is relatively distinct in vibration rather than the other structural elements. Yu et al. [14] proposed a combination method of external sensor board and smartphone by a serial port or Wi-Fi interface to improve measurement accuracy, integrated high-precision micro electromechanical system (MEMS) sensors, and then validated its accuracy through vibration test on a threelayer steel frame model. Feng et al. [15] and Ozer et al. [16] studied the utilization of accelerometers embedded in smartphone for measuring different types of vibration and validated its capability for SHM through vibration response test on a reinforced concrete pedestrian bridge. Tan and Chen [17] verified the sensitivity and accuracy of smartphone inner sensors for measuring different vibration patterns such as sinusoidal waves of various frequencies, sinusoidal sweep, and earthquake waves through shaking table tests.
Tests results demonstrated that the measurement accuracy of smartphones mainly depends on the type of vibration, the vibration directions, and the installation manner. Zhao et al. [18-20] performed the hoisting monitoring for structural members of bridge based on real-time monitoring information feedback between one controller smartphone and several collector smartphones and also developed displacement monitoring software D-Viewer, which enable monitoring of structural dynamic displacements by recognizing a laser spot centroid or predefined circle target via smartphone camera. Meanwhile, an international data sharing platform for cloudSHM based on smartphone has been established, which is possible to upload the SHM data information collected by smartphone application Orion-CC and share with the public. Peng et al. [21] developed smartphone software EExplorer using mobile Bluetooth communication technology to realize information delivery without any external network in the emergency events such as earthquake. As can be seen from the above studies, the research of SHM based on smartphone has developed rapidly and received considerable attention from numerous countries. Furthermore, it progresses from the previous single smartphone monitoring to multismartphones monitoring and from local monitoring to global data sharing, and the parameter has also expanded from acceleration as traditional measuring parameter to multiparameters such as displacement and angle.

This paper carries out a comprehensive experimental study on the major structural members of cable-stayed bridge including deck and cable to verify the feasibility of the utilization of smartphone in the quick bridge health monitoring. First, one novel cable force measurement method is proposed, which enables the estimation of cable force based on the recognition for cable vibration using smartphone camera. And then comprehensive monitoring test regarding multiple structural parameters such as accelerometer, displacement, and angle is conducted on the bridge deck. The test results demonstrate the feasibility, accuracy, and reliability of bridge health monitoring method using smartphones.

\section{D-Viewer and Orion-CC}

Smartphone application provides users with a tool for extracting structural performance parameters by various integrated sensors, processing data automatically, and transmitting data wirelessly to a central server. D-Viewer and OrionCC (Orion-Cloud Cell) are typical iOS (iPhone Operating System) smartphone applications developed by our research group for Structural Health Monitoring using smartphone, which are currently available for free at the iTunes Store $[22,23]$.

2.1. D-Viewer. In SHM practice, the displacement monitoring of bridges has an important effect on the evaluation of the structural safety and the damage detection. Recently, the laser projection-sensing technology has attracted growing interest for monitoring displacement in the field of bridge health monitoring owing to its low cost and ease of operation over traditional measuring methods [24]. 


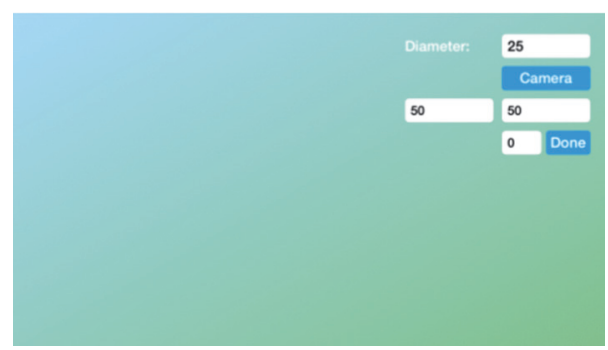

FIgURE 1: Initial setup interface.

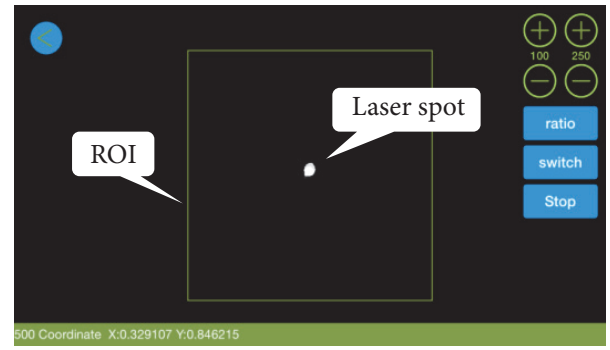

FIgURE 2: Monitoring interface.

D-Viewer is a smartphone application for monitoring structural dynamic displacement with the aid of laser device and projection plate. A laser device is installed on the monitored object, the movement of the laser spot shot on the projection plate is recognized by the camera of smartphone, and then the real-time structural displacement is obtained by means of image processing method. Figure 1 shows the initial setup interface. In this interface, the region of interest (ROI) and the function of front or rear camera can be selected for recognizing the movement of the laser spot; the diameter of a black circle as the calibration reference can be set to determine the ratio between the actual size and the pixel size of the black circle in advance. The interface of displacement monitoring is shown in Figure 2. Further details regarding operation guide and image processing method can be found in [18].

D-Viewer was designed to identify a black circle as well as the laser spot shot on the projection as shown in Figure 3; therefore, the structural static and dynamic displacements can be obtained easily by recognizing the movement of the preprinted black circle target attached on the structure using smartphone camera without laser device and projection plate, moreover, without professional expensive displacement sensors.

2.2. Orion-CC. Orion-CC was built for iOS 7.0 or higher platform, which can obtain not only acceleration and angle but also cable force by measuring structural vibration with the smartphone-embedded accelerometer and gyroscope. Figure 4 shows three screenshots of the iOS (iPhone Operating System) application interface, which enables users to interact with the smartphone sensors.

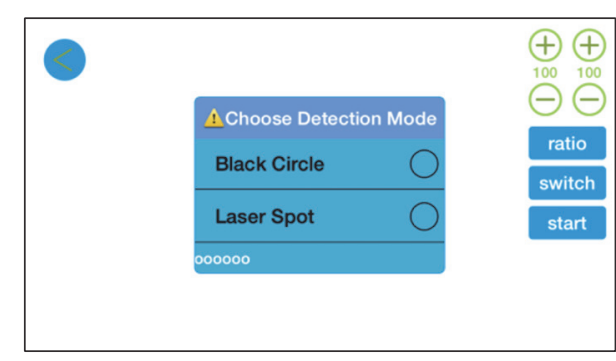

FIGURE 3: Interface of selecting a monitoring method.

Orion-CC utilizes vibration method based on the iPhone built-in accelerometer to measure the cable force. In engineering application, the vibration method by which cable forces are estimated from measured frequency difference is often used for the measurement of cable forces due to its simplicity and speediness. In general, the frequency difference and the force calculation precision are influenced by mass, length, stiffness, and sag of the cable. Orion-CC uses the relationship between the frequency difference and cable force shown in (1), in which the effects of sag and stiffness are ignored to measure cable forces rapidly and conveniently using smartphone [25].

$$
T=4 m l^{2}(\Delta f)^{2},
$$

where $m$ is the linear mass density, $l$ is the cable length, and $\Delta f$ is the frequency difference. The main function interface of cable force calculation is shown in Figure 5.

According to the cable vibrations, the power spectral density can be obtained from the acceleration time-history using FFT. And then the peak picking method is applied to extract the frequency difference from the power spectral density of the response acceleration. Finally, the cable force is estimated according to the cable length, cable linear density, and frequency difference. The interactive interface of Orion-CC reduces the need for professional training, as shown in Figures 4 and 5. Therefore, the cable force can be extracted directly and rapidly by the application OrionCC without any professional inspection device and training. Orion-CC is a valuable tool for an actual application of Structural Health Monitoring (SHM) because the cable force measuring method by Orion-CC has many advantages over other measuring methods, such as economy, convenience, and ease of operation.

\section{Vision-Based Cable Force Measuring Test}

3.1. Overview of Experiment. As mentioned before, the structural static and dynamic displacements can be obtained easily by recognizing the movement of not only a laser spot but also a black circle target, by means of smartphone camera. Based on this fact, the cable force test on the model cable is conducted in order to investigate the feasibility of a novel vision-based cable force measuring method using smartphone.

The cable model is installed in the Bridge Lab of Dalian University of Technology. The model is a $15.53 \mathrm{~m}$ single 


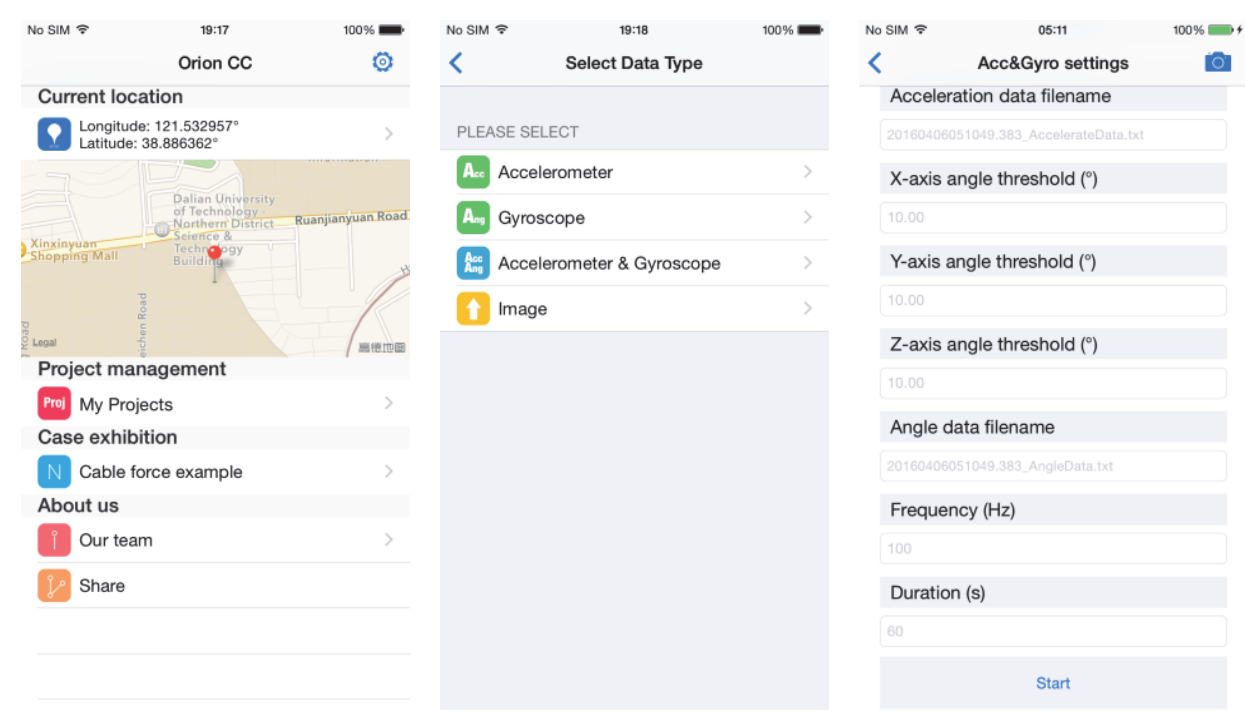

Figure 4: Main interface of Orion-CC.
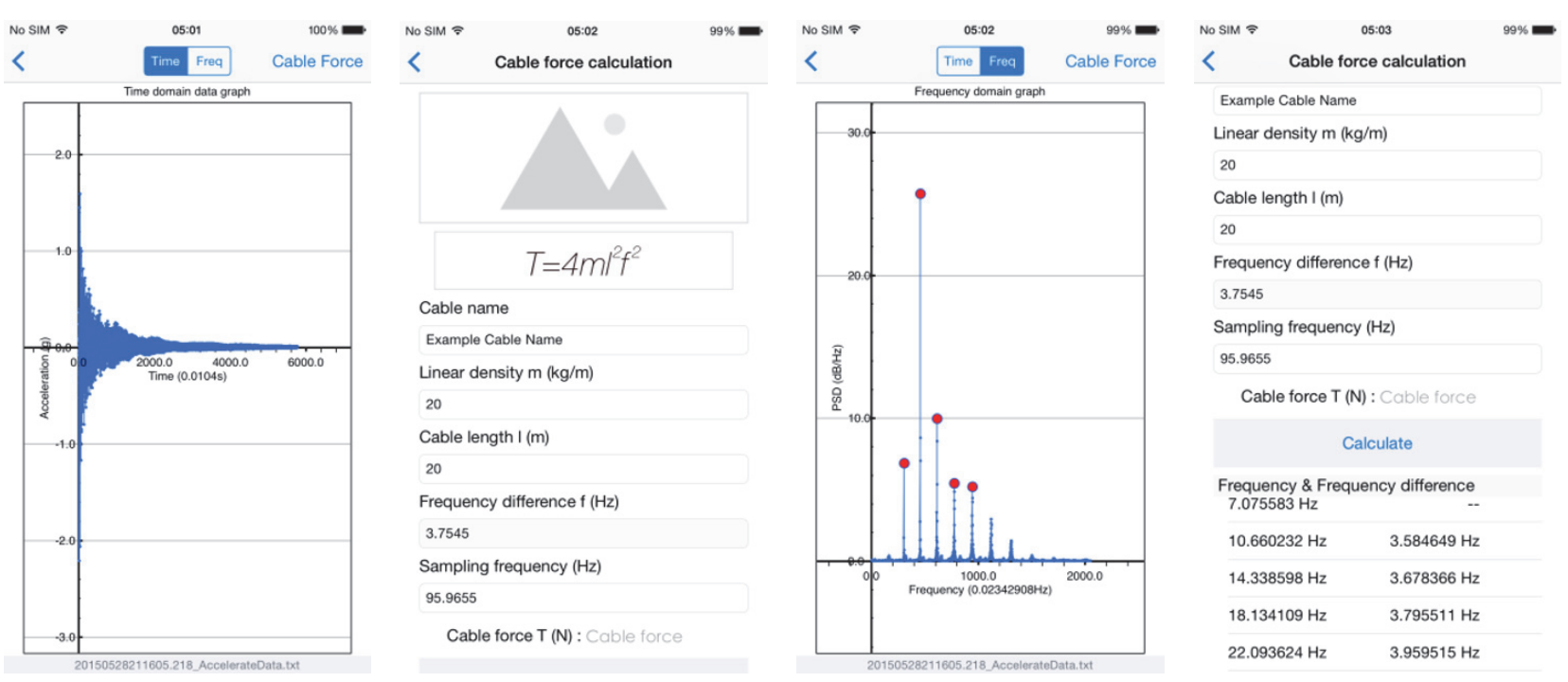

Figure 5: Main function interface of cable force calculation.

cable, and its linear mass density is $3.95 \mathrm{~kg} / \mathrm{m}$. As the smartphone for experiment, two smartphones, iPhone 6, are used; the one installed with APP D-Viewer is mounted on a tripod via double-sided adhesive tape in order to extract vibration characteristics of cable for determining cable force using smartphone camera, while the other installed with APP Orion-CC is fixed on the cable model via mobile phone jacket to obtain cable force using smartphone builtin accelerometer. An organic glass panel, on which there is a preprinted black circle, is attached to the model cable using superglue. The distance between smartphone and cable model is adjusted using the tripod according to the size of panel in order to ensure a whole white background. Figure 6 shows the installation of smartphones, and Table 1 shows the relevant parameters of iPhone 6 used in test [26].

Orion-CC is designed to collect data with a sampling rate of $100 \mathrm{~Hz}$, and the sampling rate of D-Viewer is $30 \mathrm{~Hz}$; namely, it is the same as the frames per second (fps) of smartphone camera. Both of smartphones collect the vibration data of the cable simultaneously under the artificial excitation for one minute.

3.2. Test Results. Since the focus of this test is on the verification of feasibility of cable force measurement method using smartphone camera, the vibration data of the model cable acquired by Orion-CC and D-Viewer is analyzed using MATLAB. Figures 7 and 8 plot the acceleration and displacement time histories obtained, respectively, from D-Viewer and Orion-CC, together with corresponding PSD results.

As shown in figures, although the vibration amplitudes and PSD peak values are different due to the differences of sampling rate, measuring position, and measuring item, it is observed that the same frequency components can be accurately obtained by the different methods from both of 
TABLE 1: Relevant parameters of iPhone 6.

\begin{tabular}{lcccc}
\hline $\begin{array}{l}\text { Operating } \\
\text { system }\end{array}$ & Display & Chips & Video recording & Sensors \\
\hline & Retina HD display & & & Barometer \\
I.7-inch (diagonal) & A8 chip with 64-bit architecture & 1080 p HD video recording & Three-axis gyro \\
& 1334-by-750-pixel resolution & Accelerometer \\
& at 326 ppi & M8 motion coprocessor & (30 fps or 60 fps) & Proximity sensor \\
& $1400: 1$ contrast ratio (typical) & & Ambient light sensor \\
\hline
\end{tabular}

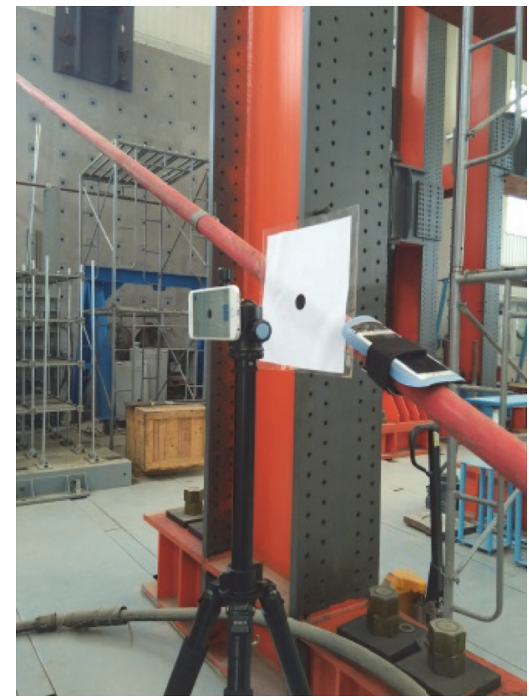

FIGURE 6: The installation of smartphones.

smartphone applications. Moreover, it is noteworthy that the natural frequency of the first vibration mode for estimating cable force can be accurately obtained by the displacement response measurement of the cable using the application DViewer. In general, as the position at which smartphone is mounted is relatively low compared with the length of cable, the first peak in the corresponding PSD obtained by the vibration measurement of cable is not very clear, and thus it is usually difficult to identify the natural frequency of the first vibration mode for estimating cable force by the application Orion-CC using smartphone built-in accelerometer. As can be seen from Figure $8(\mathrm{~b})$, it is impossible to extract the natural frequencies at the higher mode (above $15 \mathrm{~Hz}$ ) by the application D-Viewer because of its low sampling rate. However, the result shows that the frequency components can be accurately obtained in the lower frequency domain, and it is clear that the fps of smartphone camera will be increased along with the improvement of smartphone performance in the future.

The frequency difference is obtained by means of peak picking method from PSD, and the cable force is determined from (1). Table 2 summarizes the frequency difference and cable force identified by two methods. As can be seen from Table 2, the cable forces obtained by D-Viewer and Orion-CC are highly comparable, with significantly small error of less than $1.1 \%$. Therefore, it is concluded that vision-based cable
TABLE 2: Comparison of the results from Orion-CC and D-Viewer.

\begin{tabular}{lcc}
\hline Item & Frequency difference $(\mathrm{Hz})$ & Cable force $(\mathrm{KN})$ \\
\hline Orion-CC & 3.72 & 52.466 \\
D-Viewer & 3.70 & 51.904 \\
Error $(\%)$ & 0.54 & 1.07 \\
\hline
\end{tabular}

force measurement using smartphone camera is feasible in the sampling rate of $30 \mathrm{fps}$.

\section{Smartphone-Based Structural Health Monitoring Testing}

4.1. Overview of Experiment. In order to investigate the implementation feasibility of the quick bridge health monitoring technique using smartphone, a comprehensive experiment is conducted for a laboratory-scale suspension bridge. The test focuses on the identification of natural frequency through the extraction of vibration response of different physical indices such as acceleration, displacement, and angle in different locations using smartphone application.

As the experiment object, a concrete self-anchored suspension bridge model, which is designed and constructed with $1 / 28$ scale of Zhuanghe Construction Bridge located in Zhuanghe city of China shown in Figure 9, is selected in the Bridge Lab of Dalian University of Technology. This scale bridge model consists of a main span of $7.14 \mathrm{~m}$, a box girder of reinforced concrete, main cables and hangers of twisted wire rope, and two towers.

To measure the dynamic characteristics of the bridge model, three smartphones and acceleration sensors are installed at mid span and one-quarter spans of the model via double-sided adhesive tape, respectively. The reference coordinate of smartphone for measuring vibration responses is shown in Figure 10.

Also the displacement monitoring system using smartphone, including a laser transmitter and a projection plate, is mounted on the bridge model to measure the displacement response of mid span. A sheet of A4 white paper, on which a black circle of $25 \mathrm{~mm}$ in diameter is preprinted, is attached to projection plate, and then the calibration is conducted in the initial setup interface for measuring. The laser transmitter is fixed at one end of the bridge model to remain stationary during experiment. To verify the accuracy of the displacement monitoring method based on the smartphone, a laser displacement sensor is fixed by means of steel frame at the 


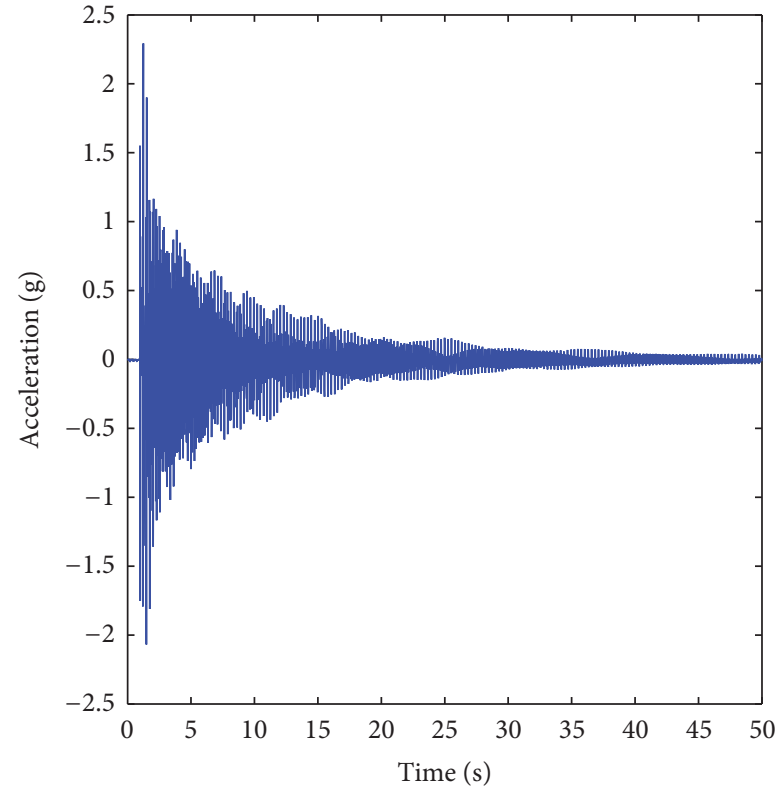

(a) Acceleration time history

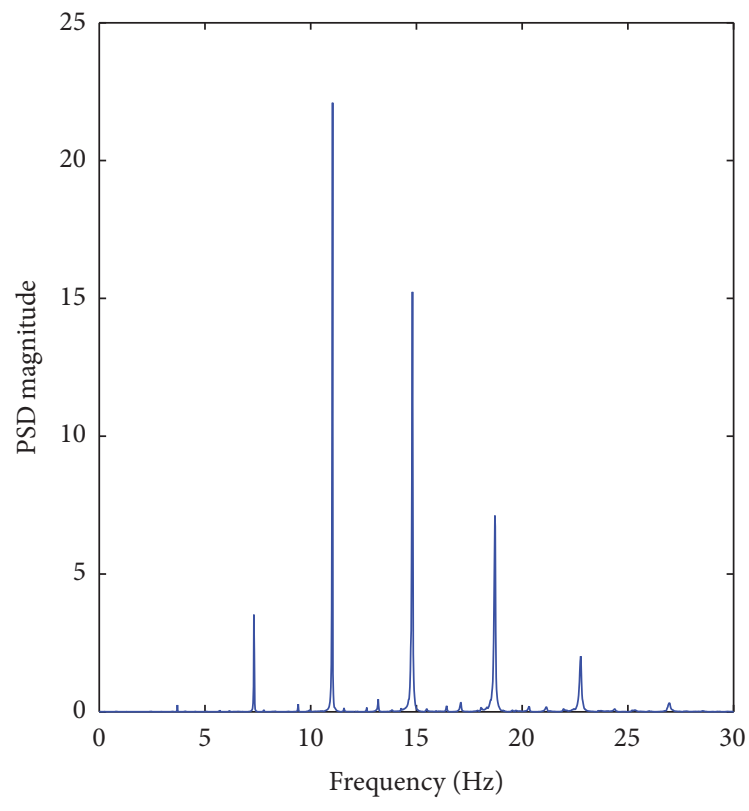

(b) Corresponding PSD

FIgURE 7: Results of Orion-CC.

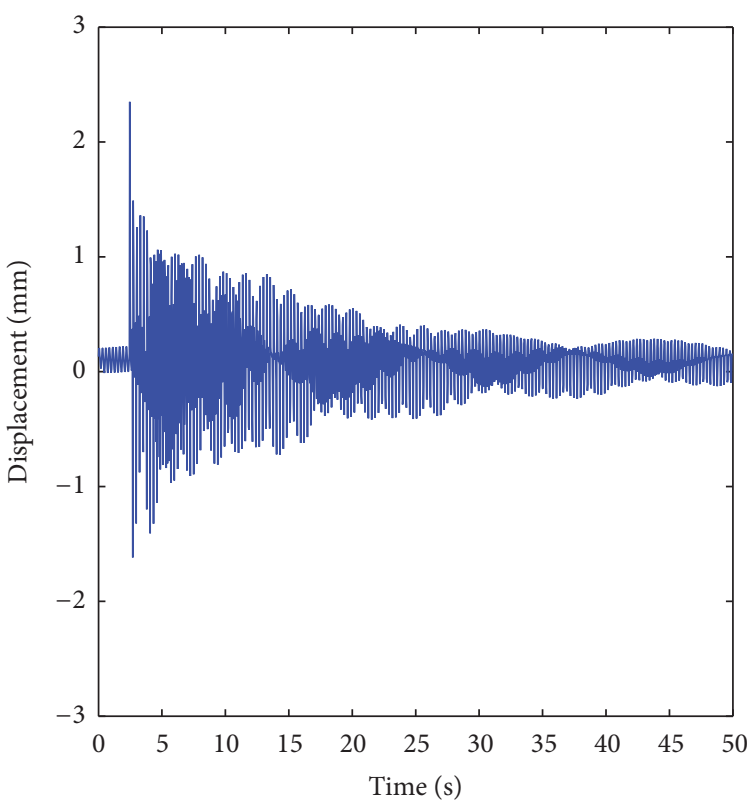

(a) Displacement time history

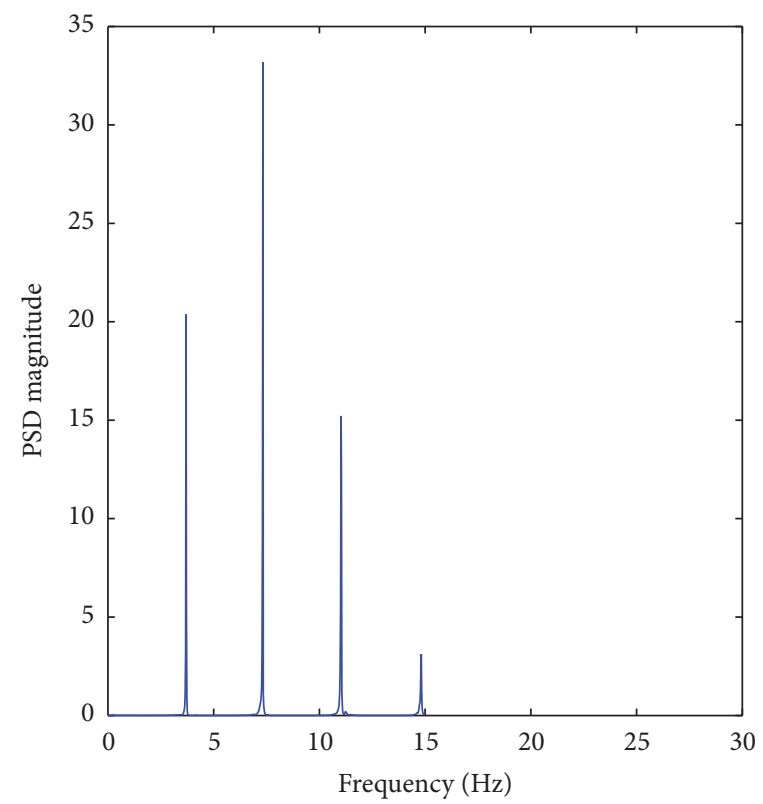

(b) Corresponding PSD

Figure 8: Results of D-Viewer.

mid span of the model. The main instrument parameters are indicated in Table 3.

All of the four smartphones used in experiment are iPhone 6 with a three-axis Bosch BMA280 accelerometer [27], a three-axis InvenSense MPU-6500 accelerometer, and a three-axis InvenSense MPU-6500 gyroscope [28]. The properties of two accelerometers and gyroscope are listed in Tables 4 and 5.
As mentioned before, the dynamic responses of acceleration and angle in the vibration of structure can be obtained by the application Orion-CC using the smartphone-embedded accelerometer and gyroscope, and also the dynamic displacement response of the structure can be extracted by recognizing the movement of the laser spot shot on the projection plate by means of the application $\mathrm{D}$-Viewer using smartphone camera. 
TABLE 3: Main instruments parameters.

\begin{tabular}{lccc}
\hline Instrument & Brand & Model & Parameter \\
\hline Piezoelectric accelerometer & SINOCERA & CA-YD-188 & $\begin{array}{c}\text { Sensitivity: } 500 \mathrm{mV} / \mathrm{g} \pm 5 \% \\
\text { Measurement range: } 10 \mathrm{~g} \\
\text { Frequency range: } 0.3-2500 \mathrm{~Hz}\end{array}$ \\
\hline Laser displacement sensor & MICR-EPSILON & ILD 11300 & $\begin{array}{c}\text { Measuring range: } 50 \mathrm{~mm} \text { to } 150 \mathrm{~mm} \\
\text { Resolution (dynamic): } 100 \mathrm{microns}\end{array}$ \\
\hline Laser transmitter & Ruic & Red-light semiconductor laser & $\begin{array}{c}\text { Output wavelength: } 650 \mathrm{~nm} \\
\text { Overall dimensions: } \Phi 20 \mathrm{~mm} \times 90 \mathrm{~mm} \\
\text { Light spot diameter is } 3 \mathrm{~mm} \text { at a } 20 \mathrm{~m} \text { distance }\end{array}$ \\
\hline
\end{tabular}

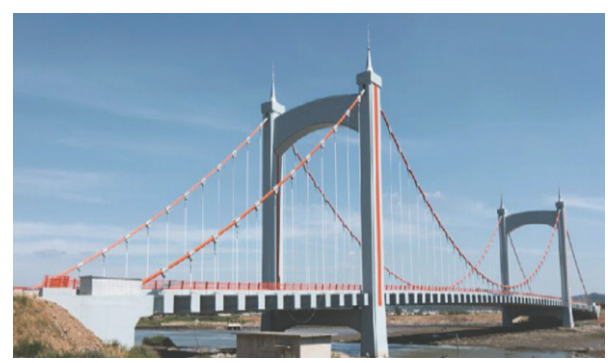

Figure 9: Zhuanghe Construction Bridge.

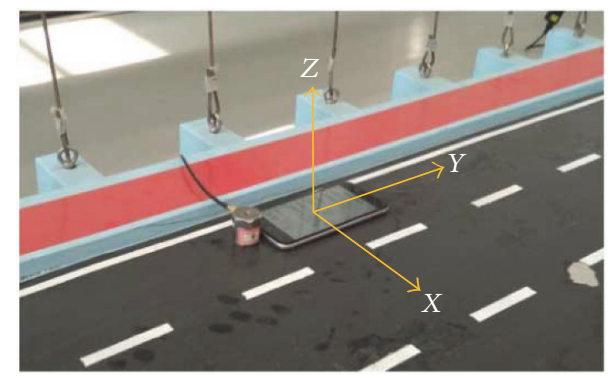

FIGURE 10: The reference coordinate system of smartphone.

In this experiment, three smartphones (1 (left), 2 (mid), and 3 (right)) installed with Orion-CC are used to measure both acceleration and angle responses of the model with a sampling rate of $100 \mathrm{~Hz}$, and the other smartphone (4 (mid)) installed with D-Viewer monitors the dynamic displacement of the mid span of the model with a sampling rate of $30 \mathrm{~Hz}$. All of reference sensors are connected to a sensor node through cable, respectively, and the vibration responses are recorded in computer during measurement. The scale bridge model and the layout of the smartphone and sensors are shown in Figure 11. The test is carried out simultaneously under the artificial impact excited on the mid span.

4.2. Test Results. The vibration responses obtained from smartphones and sensors are compared in both time and frequency domains. The natural frequency of the bridge model is identified by the peak picking method from the power spectral densities of different vibration responses. For brevity, the $z$-axis (direction of gravity) acceleration responses and the rotation angle responses around $x$-axis
TABLE 4: Bosch BMA280 and InvenSense MPU-6500 accelerometer properties.

\begin{tabular}{lccc}
\hline Parameter & Bosch BMA280 & $\begin{array}{c}\text { InvenSense } \\
\text { MPU-6500 }\end{array}$ & Units \\
\hline Digital resolution & 14 & 16 & Bits \\
\hline \multirow{3}{*}{ Full-scale range } & \pm 2 & \pm 2 & $\mathrm{~g}$ \\
& \pm 4 & \pm 4 & $\mathrm{~g}$ \\
& \pm 8 & \pm 8 & $\mathrm{~g}$ \\
& \pm 16 & \pm 16 & $\mathrm{~g}$ \\
\hline Sensitivity scale & 4096 & 16384 & $\mathrm{LSB} / \mathrm{g}$ \\
& 2048 & 8192 & $\mathrm{LSB} / \mathrm{g}$ \\
& 1024 & 4096 & $\mathrm{LSB} / \mathrm{g}$ \\
Cross-axis sensitivity & 1 & 2048 & $\mathrm{LSB} / \mathrm{g}$ \\
\hline Nonlinearity & 512 & 2 & $\%$ \\
\hline Zero-g offset & 0.5 & 0.5 & $\%$ \\
\hline Noise density & \pm 50 & \pm 60 & $\mathrm{mg}$ \\
\hline
\end{tabular}

TABLE 5: InvenSense MPU-6500 gyroscope properties.

\begin{tabular}{lcc}
\hline Parameter & Technical data & Units \\
\hline Digital resolution & 16 & Bits \\
\hline & \pm 250 & $\% / \mathrm{s}$ \\
Full-scale range & \pm 500 & $\% / \mathrm{s}$ \\
& \pm 1000 & $\% / \mathrm{s}$ \\
& \pm 2000 & $\%$ \\
\hline Sensitivity scale & 131 & $\mathrm{LSB} /\left({ }^{\circ} / \mathrm{s}\right)$ \\
& 65.5 & $\mathrm{LSB} /(\% \mathrm{~s})$ \\
& 32.8 & $\mathrm{LSB} /\left({ }^{\circ} / \mathrm{s}\right)$ \\
\hline Nonlinearity & 16.4 & $\mathrm{LSB} /\left({ }^{\circ} / \mathrm{s}\right)$ \\
\hline Cross-axis sensitivity & \pm 0.1 & $\%$ \\
\hline Noise density & \pm 2 & $\%$ \\
\hline Initial zero-rate output & 0.01 & $\% / \mathrm{s} / \sqrt{\mathrm{Hz}}$ \\
\hline Mechanical frequency & \pm 5 & $\mathrm{KHz}$ \\
\hline
\end{tabular}

(vertical to span direction) are used to identify the natural frequency of the bridge model.

4.2.1. Acceleration Response Results. Figures 12-14 show the acceleration time history responses, comparisons in time 

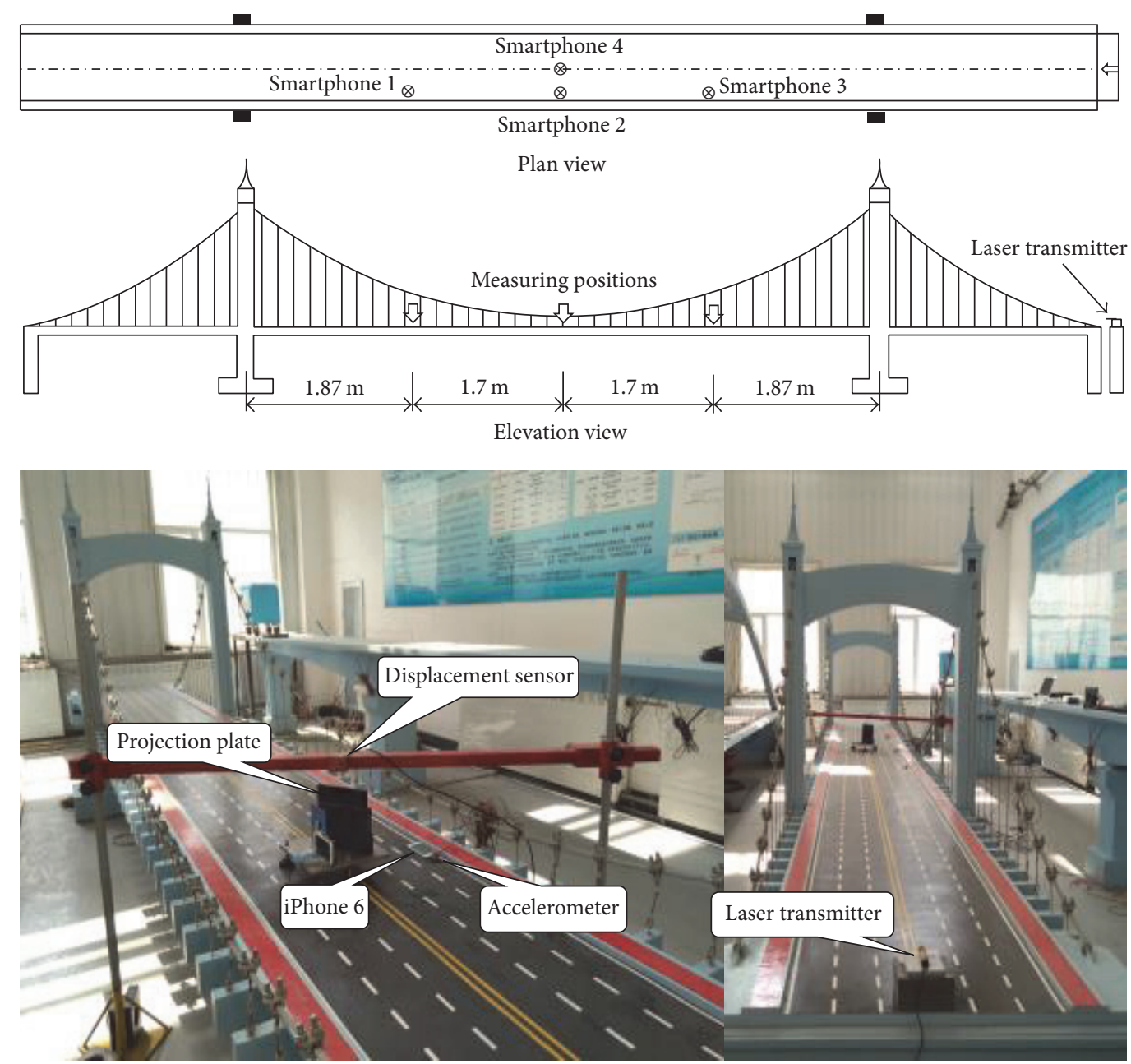

FIGURE 11: Setup of experiment.

domain, and the corresponding PSD measured by the smartphones and the reference accelerometers at three different points of the bridge model, respectively. Since the duration of vibration response on the artificial impact is less than $10 \mathrm{~s}$, the plots of comparisons in time domain are enlarged (between $4 \mathrm{~s}$ and $5 \mathrm{~s}$ ) to show more details. The peak responses are obtained as $0.38 \mathrm{~g}$ (left), $0.64 \mathrm{~g}$ (mid), and $0.29 \mathrm{~g}$ (right) by smartphones, respectively. A noticeable difference exists between the mid span and quarter span in terms of amplitude.

As can be seen from comparison figures, the measurements of smartphone agree well with the measurements of reference accelerometers in terms of amplitude characteristics. The identified natural frequencies of bridge model are summarized in Table 6. The natural frequency is identified as $4.58,4.56$, and $4.57 \mathrm{~Hz}$, respectively, at three different measuring points by three reference accelerometers. Their counterparts measured by three smartphones are 4.56, 4.57, and $4.58 \mathrm{~Hz}$. The excellent agreement is observed between the frequency values obtained by the reference accelerometers and smartphones at different measuring points, with a maximum error of $0.44 \%$.
TABLE 6: Comparison of natural frequency identified from acceleration measurements.

\begin{tabular}{lccc}
\hline Location & 1 (left) & 2 (mid) & 3 (right) \\
\hline Natural frequency (Hz) & & & \\
$\quad$ Accelerometer & 4.56 & 4.57 & 4.58 \\
$\quad$ Smartphone (Orion-CC) & 4.58 & 4.56 & 4.57 \\
Error (\%) & 0.44 & 0.22 & 0.22 \\
\hline
\end{tabular}

4.2.2. Angle Response Results. The angle time history responses and corresponding PSD measured by three smartphones at different measuring points are shown in Figures 15-18, respectively. As can be seen from Figures 16 and 18 , the angle vibration responses of the mid span obtained from smartphone 2 are not very clear in both time and frequency domains compared to the other ones because theoretically there is no change in the slope of the mid span according to the vibration in this test case. The natural frequencies extracted from PSD of angle measurements are compared with the previous ones measured by the reference accelerometers. Table 7 lists the identified natural frequency values. The natural frequency is not accurately extracted 


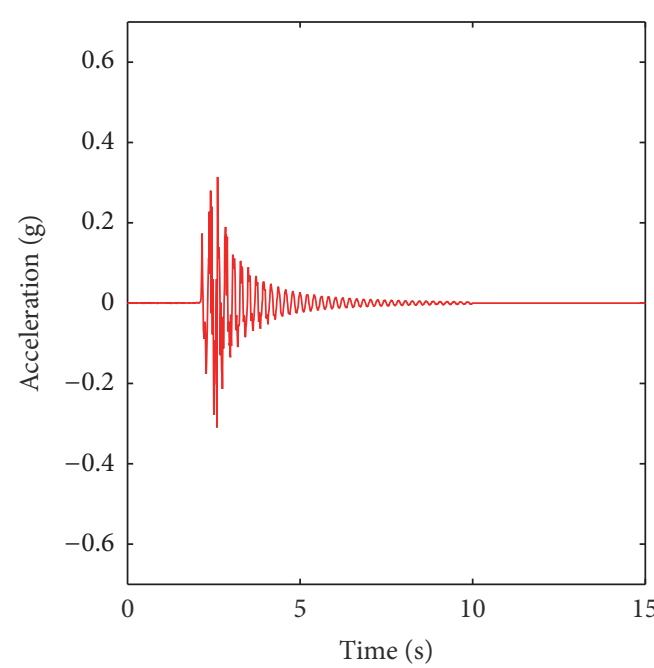

- Accelerometer 1

(a) Acceleration time history (sensor)

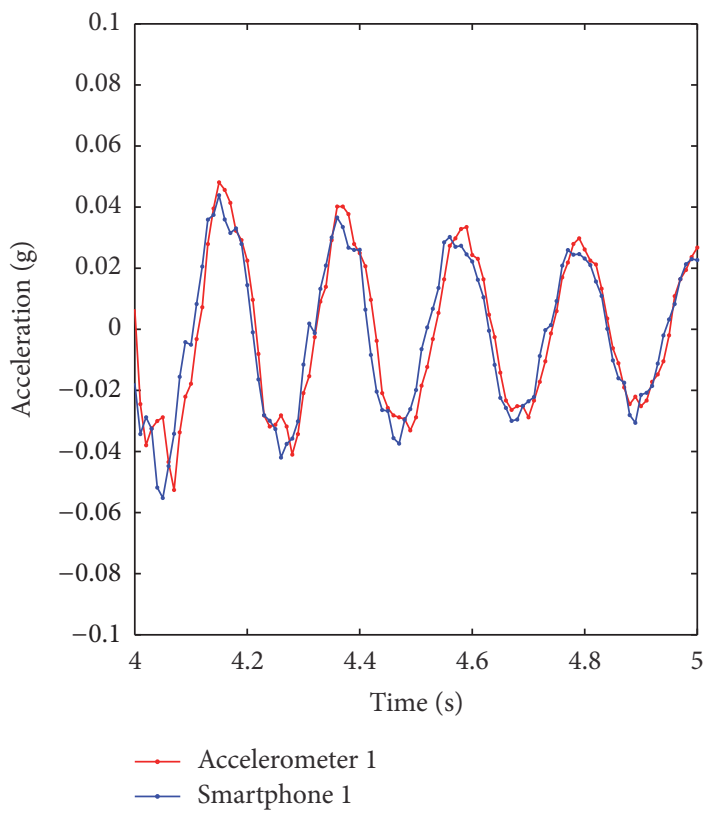

(c) Comparison

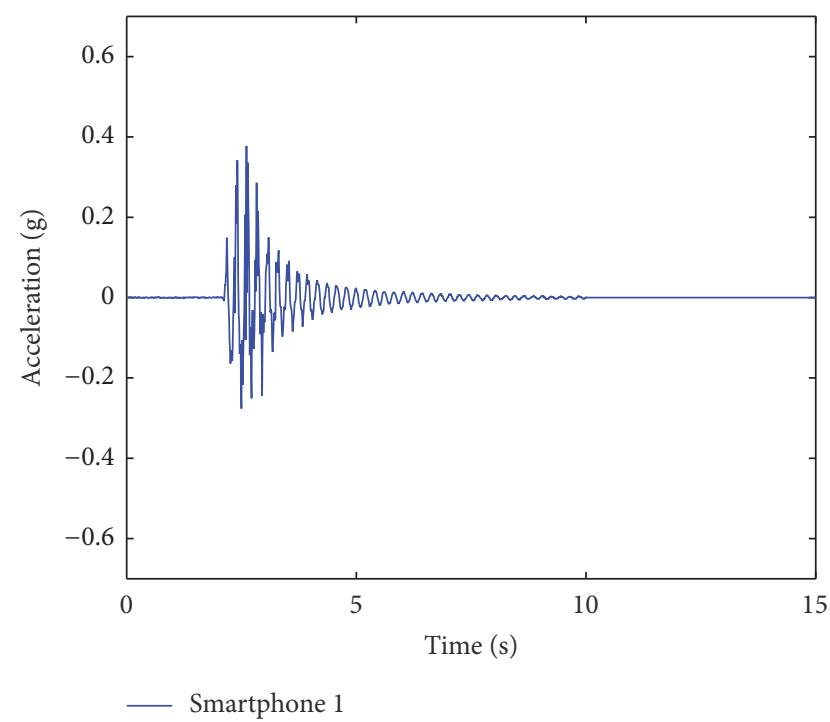

(b) Acceleration time history (smartphone)

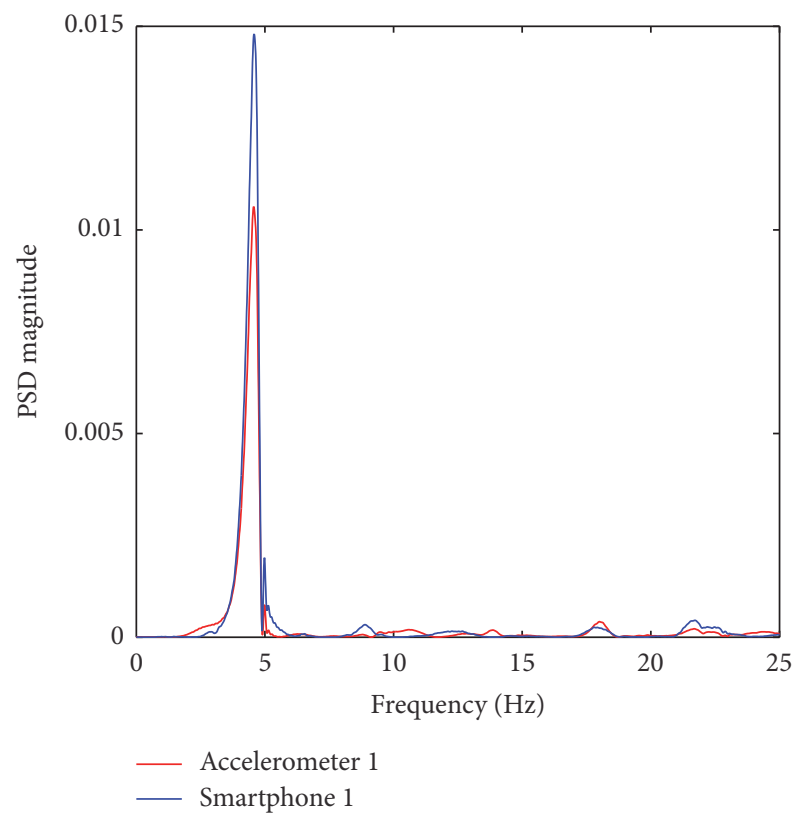

(d) Corresponding PSD

FIGURE 12: Acceleration measurements (left quarter span).

from the angle measurement of the mid span as shown in Table 7. The other ones are 4.68 and $4.59 \mathrm{~Hz}$, while their counterparts measured by the reference accelerometers are 4.56 and $4.58 \mathrm{~Hz}$. The errors in the natural frequency values at each measuring point are within $2.63 \%$. It is observed that the bridge health monitoring based on the angle measurements using smartphones is feasible and reliable.

4.2.3. Displacement Response Results. Figure 19 plots the displacement time history responses, comparisons in time domain, and the corresponding PSD obtained from smartphone 4 and the laser displacement sensor at mid span of the bridge model. The identified natural frequencies of
TABLE 7: Comparison of natural frequency identified from angle measurements.

\begin{tabular}{lccc}
\hline Location & 1 (left) & 2 (mid) & 3 (right) \\
\hline Natural frequency (Hz) & & & \\
$\quad$ Accelerometer & 4.56 & 4.57 & 4.58 \\
$\quad$ Smartphone (Orion-CC) & 4.68 & - & 4.59 \\
Error (\%) & 2.63 & - & 0.22 \\
\hline
\end{tabular}

bridge model are summarized in Table 8 . Since the sampling rate of the smartphone for displacement monitoring $(30 \mathrm{~Hz})$ is different with the reference one $(100 \mathrm{~Hz})$, the plots of 


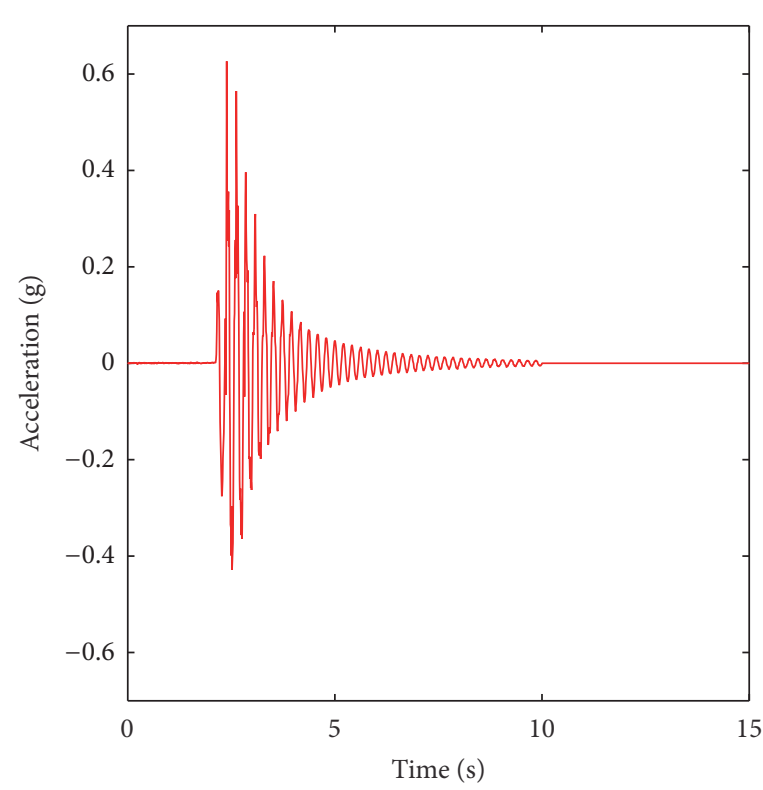

- Accelerometer 2

(a) Acceleration time history (sensor)

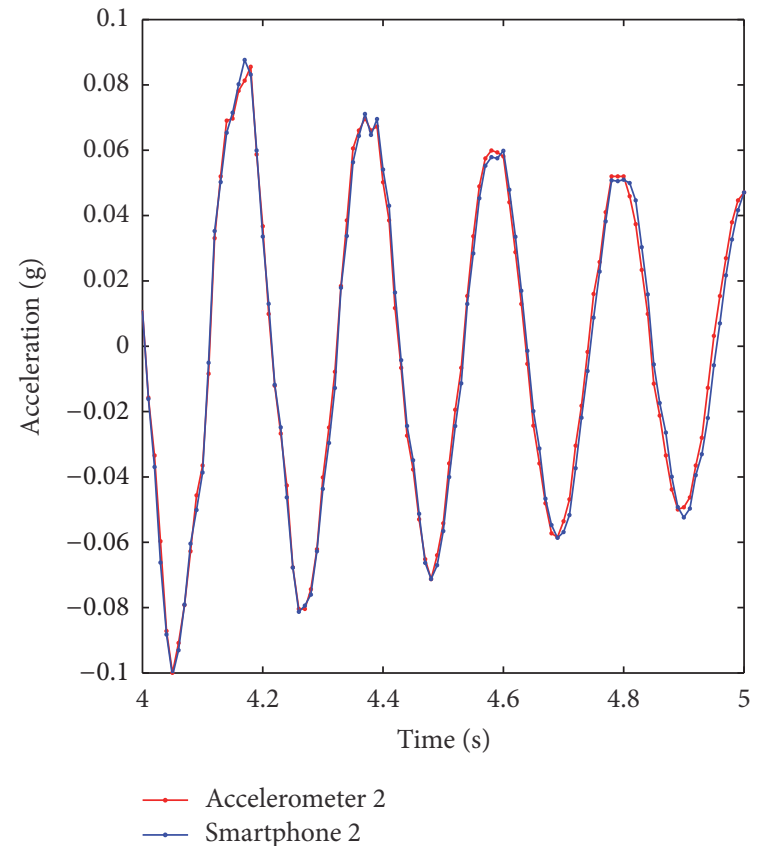

(c) Comparison

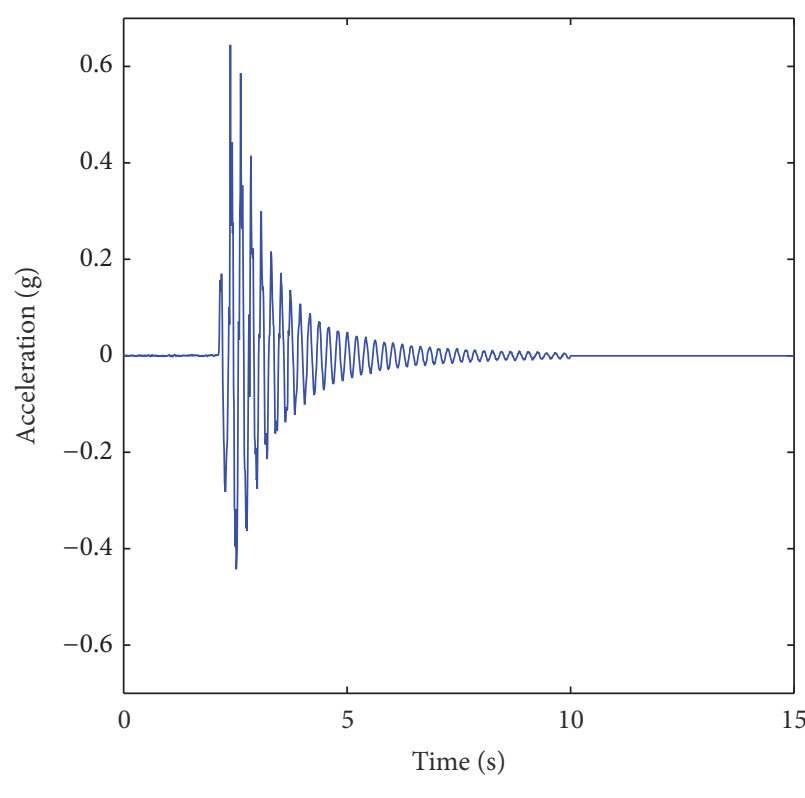

- Smartphone 2

(b) Acceleration time history (smartphone)

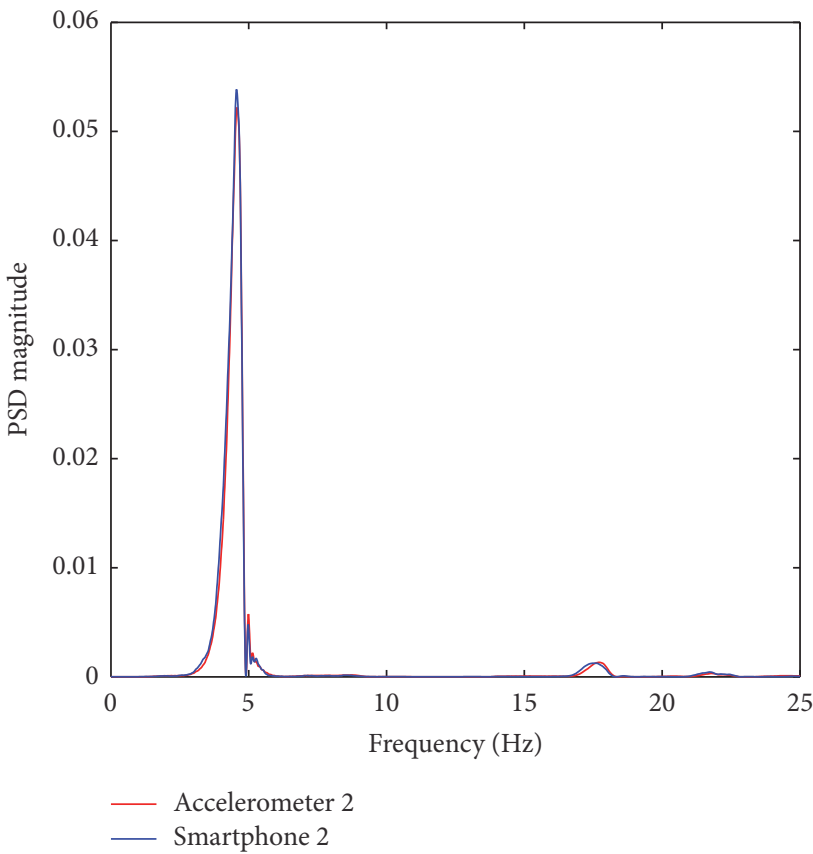

(d) Corresponding PSD

Figure 13: Acceleration measurements (mid span).

TABLE 8: Comparison of natural frequency identified from displacement measurements.

\begin{tabular}{lc}
\hline Location & 4 (mid) \\
\hline Natural frequency (Hz) & \\
Displacement sensor & 4.56 \\
Smartphone (D-Viewer) & 4.68 \\
Error (\%) & 2.63 \\
\hline
\end{tabular}

comparisons in time domain are enlarged (between $4 \mathrm{~s}$ and $5 \mathrm{~s})$ to show more details.

As can be seen in Figure 19(c), although the sampling rates are different, the displacement response time histories agree well with one another. The natural frequency of the bridge model measured by the laser displacement sensor is $4.56 \mathrm{~Hz}$, while the one measured by smartphone 4 is $4.68 \mathrm{~Hz}$. Again, the satisfactory agreement is observed between the 


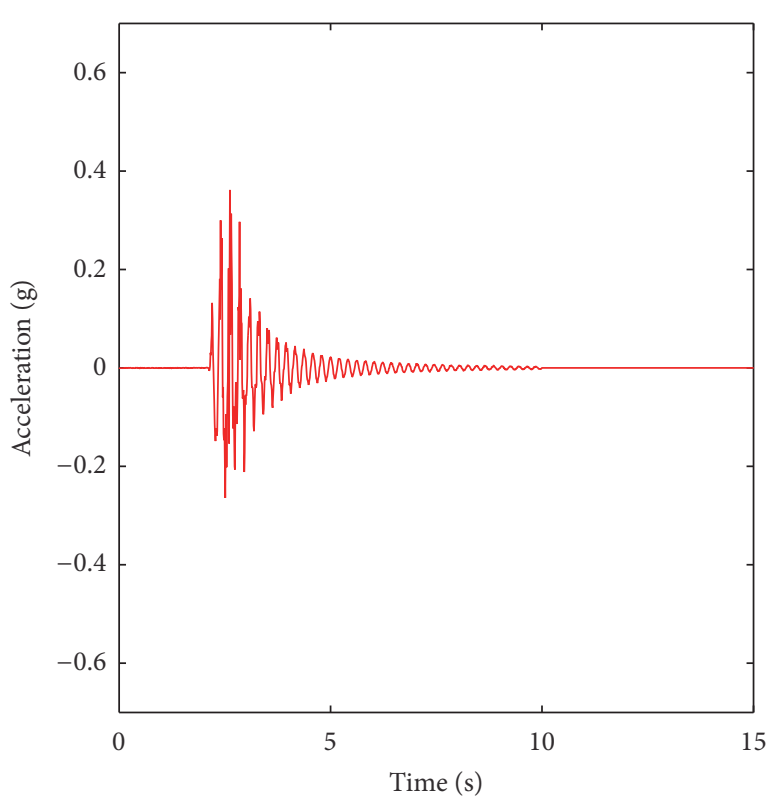

_ Accelerometer 3

(a) Acceleration time history (sensor)

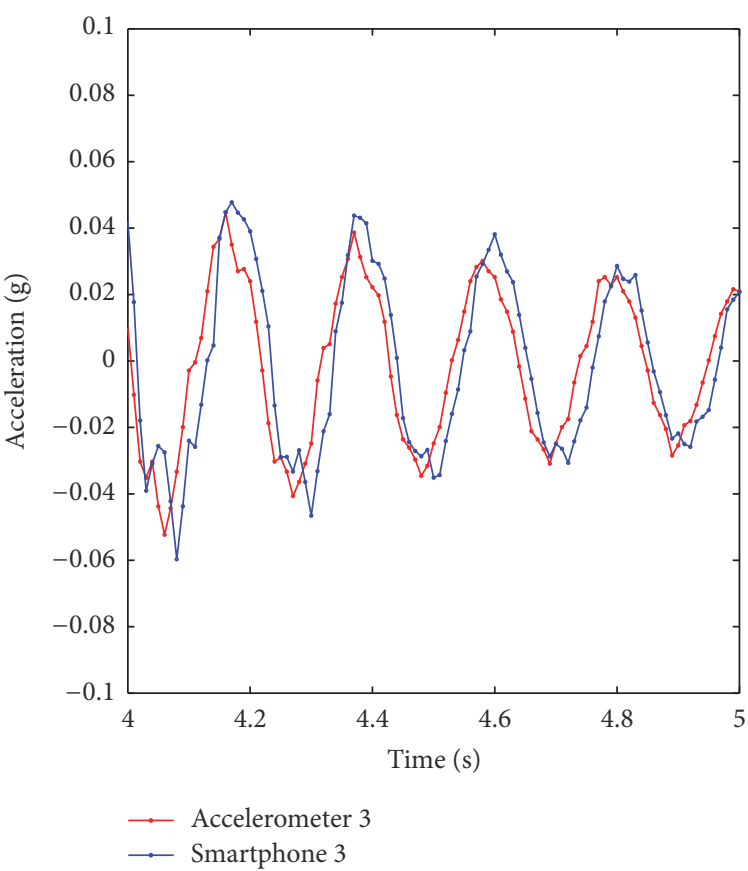

(c) Comparison

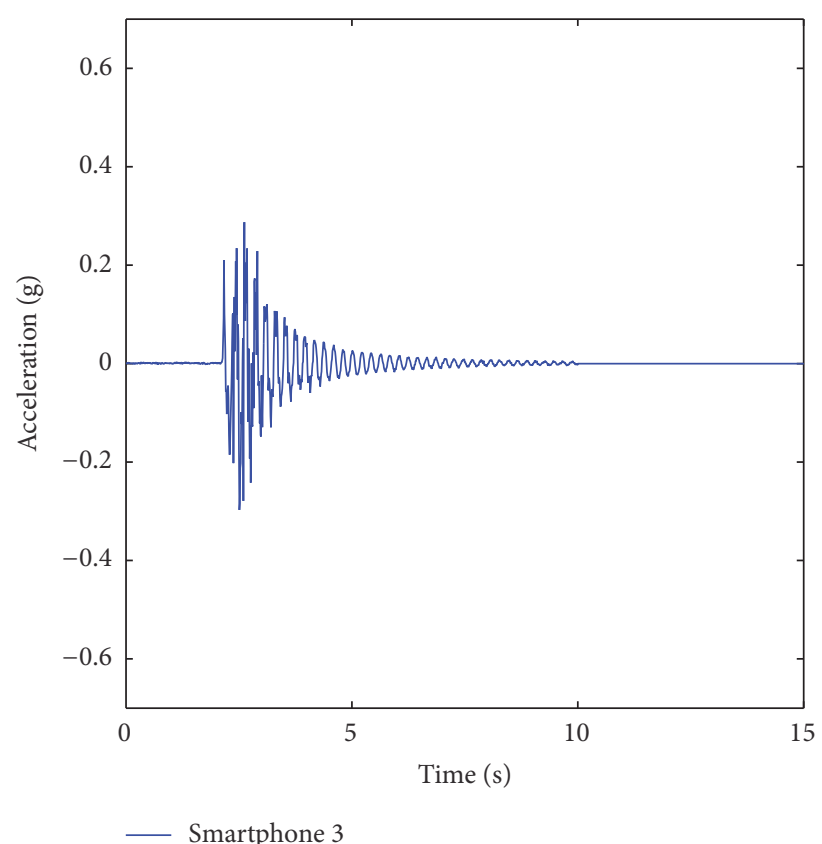

(b) Acceleration time history (smartphone)

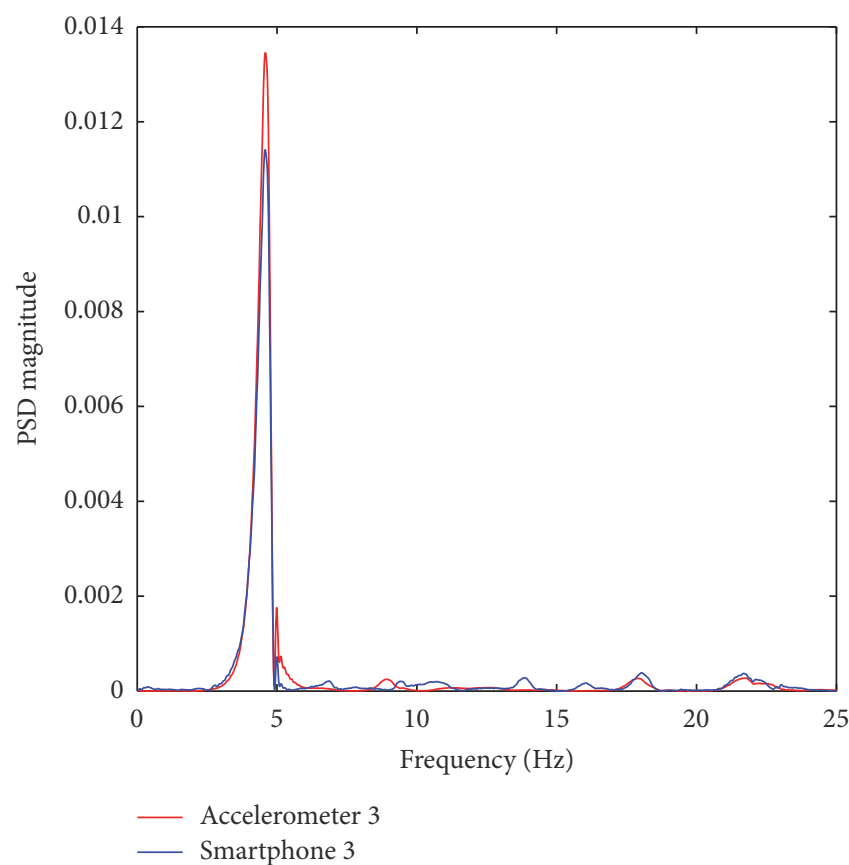

(d) Corresponding PSD

Figure 14: Acceleration measurements (right quarter span).

frequency values obtained by the reference sensor and smartphone.

\section{Conclusion}

In this study, a comprehensive experiment research, including cable force test and bridge model test, was carried out to verify the feasibility of the quick bridge health monitoring technique using smartphone. First, the vision-based cable force measurement method was proposed in this paper, and then the comparison test was conducted on the cable model to verify the feasibility of proposed method. The natural frequency components and cable forces measured by the application $\mathrm{D}$-Viewer were compared with the results measured by the application Orion-CC. While it is difficult to obtain the natural frequencies at the higher mode due 


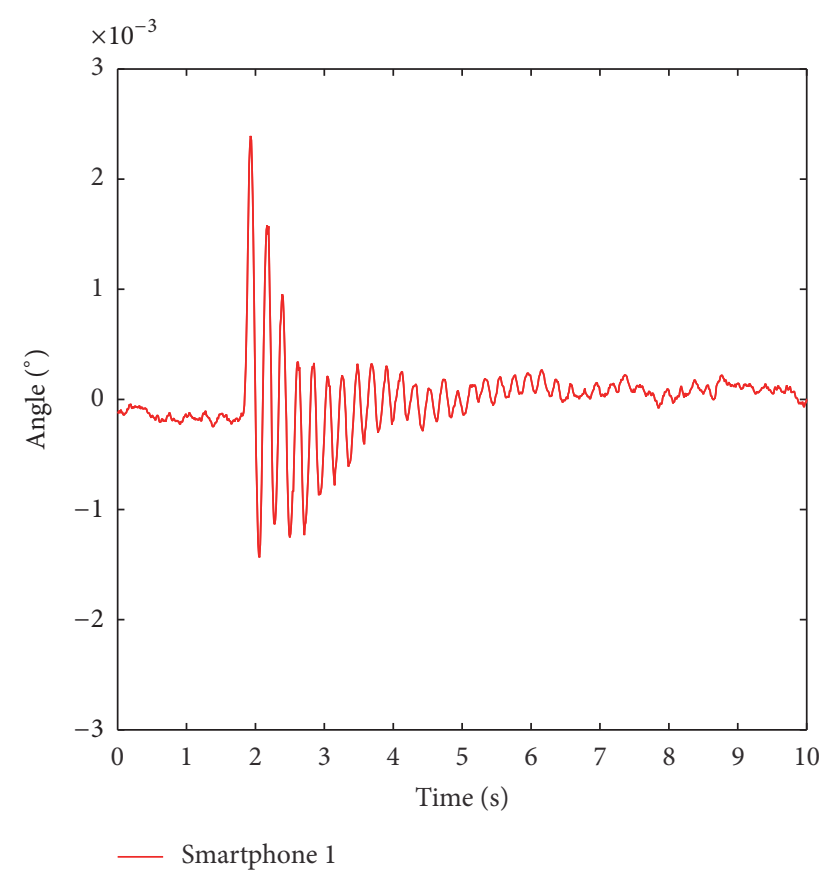

Figure 15: Angle measurement (left quarter span).

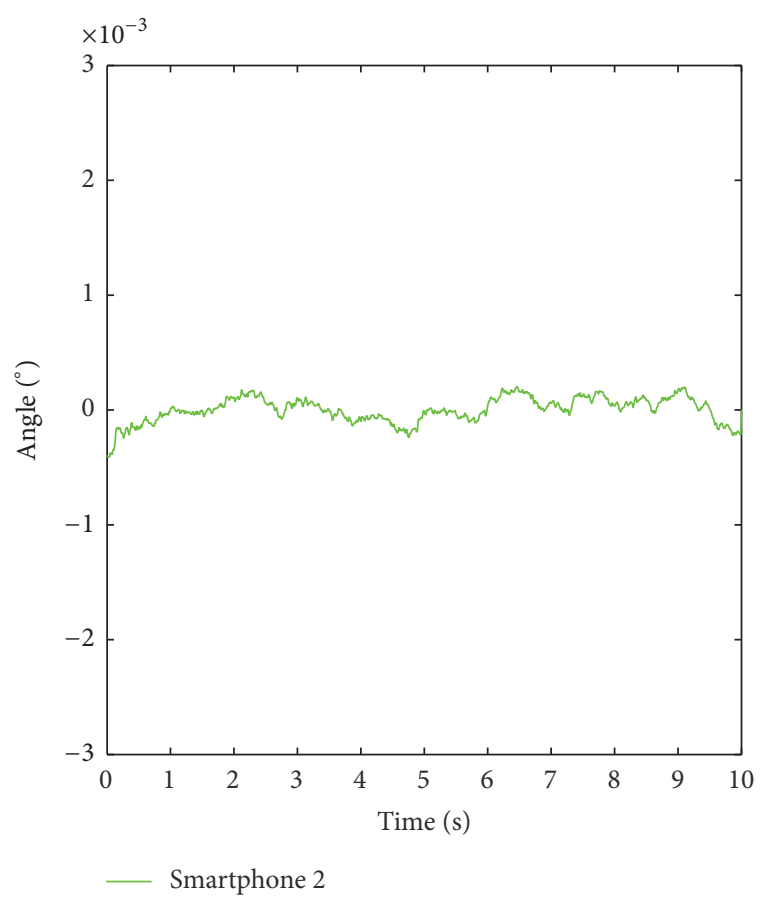

Figure 16: Angle measurement (mid span).

to the sampling rate of smartphone camera, the frequency components including the natural frequency of the first mode were estimated accurately at the lower vibration mode. The test result demonstrated the feasibility and accuracy of vision-based cable force measurement using smartphone, with significantly small error of less than $1.1 \%$. Finally, the comprehensive monitoring test regarding multiple structural

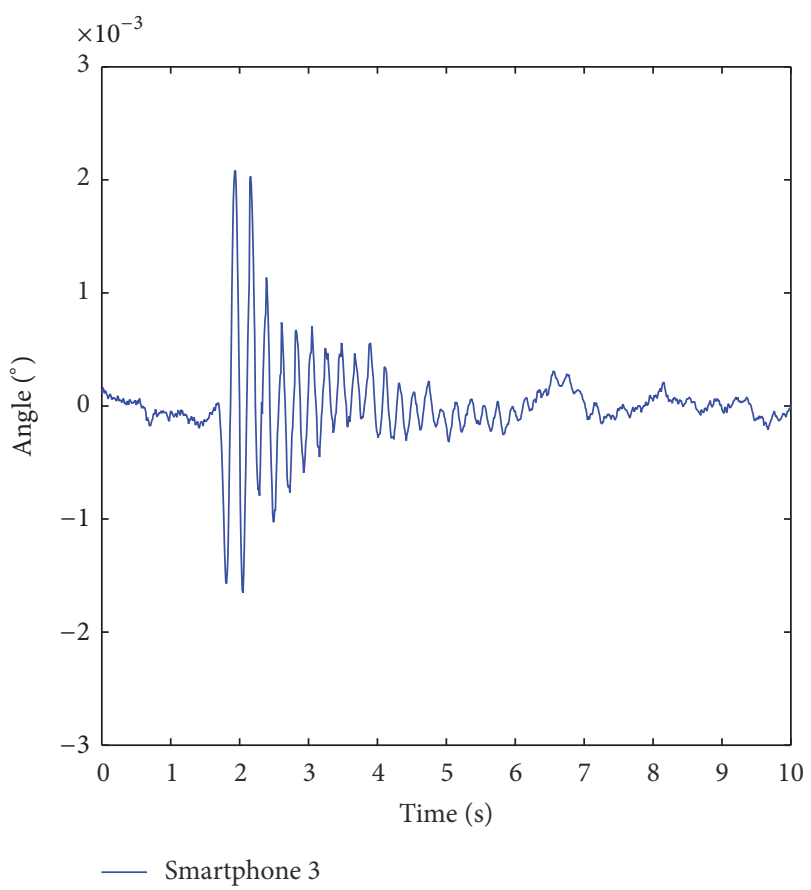

Figure 17: Angle measurement (right quarter span).

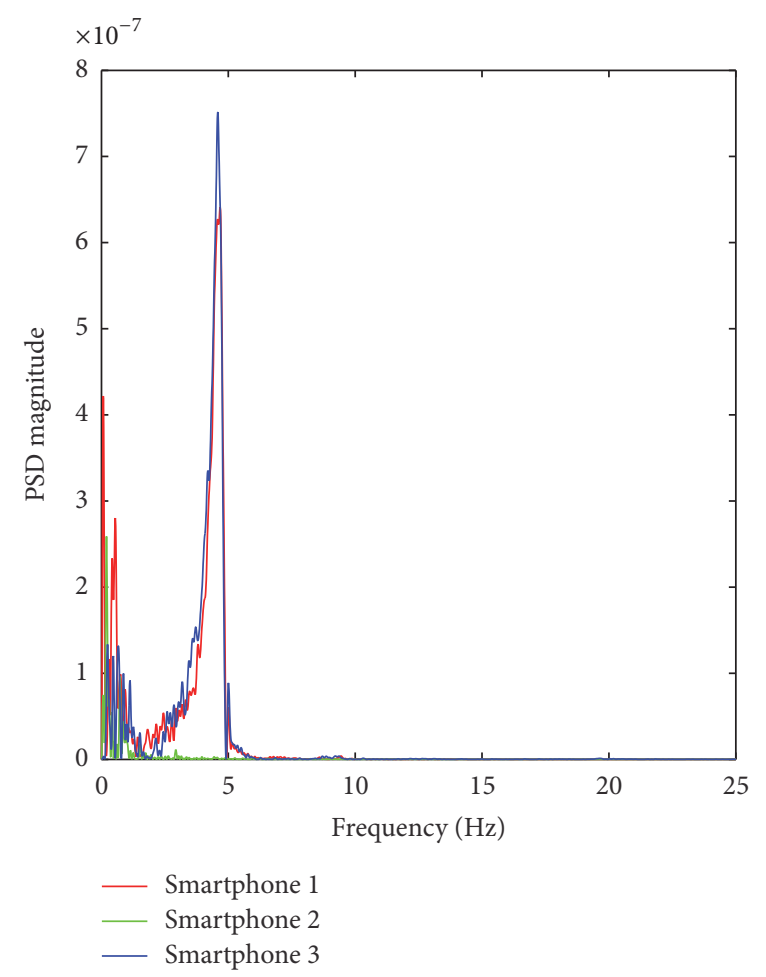

FIGURE 18: PSD of angle responses.

parameters was conducted on the scale bridge model. The vibration responses obtained from smartphones and sensors were compared in both time and frequency domains. The natural frequency of the bridge model was estimated accurately from the vibration responses of multiple structural parameters such as acceleration, angle, and displacement, 


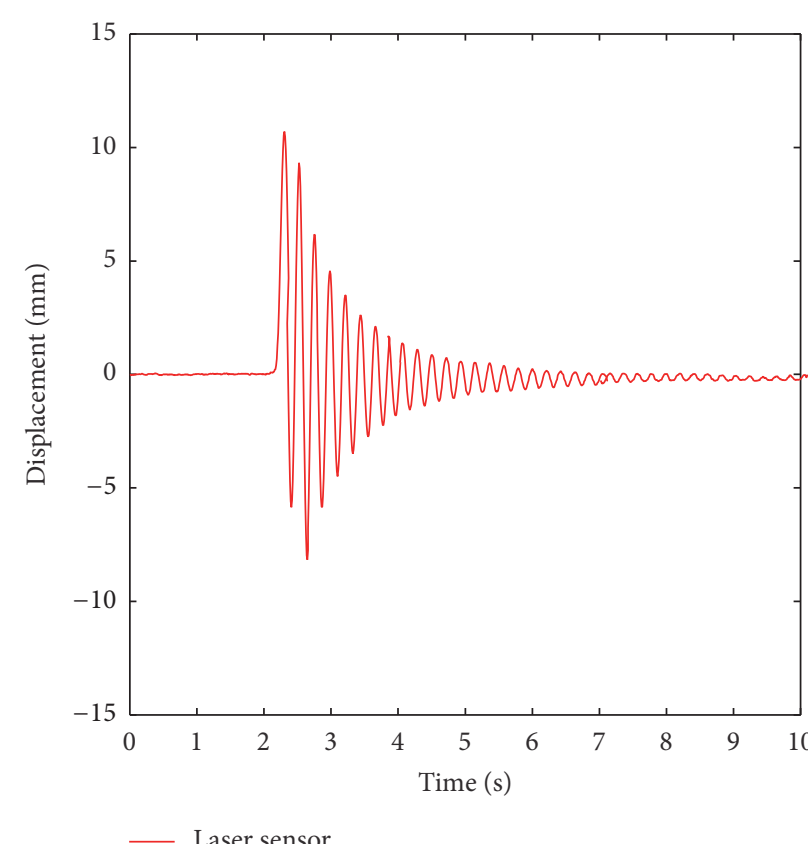

(a) Displacement time history (sensor)

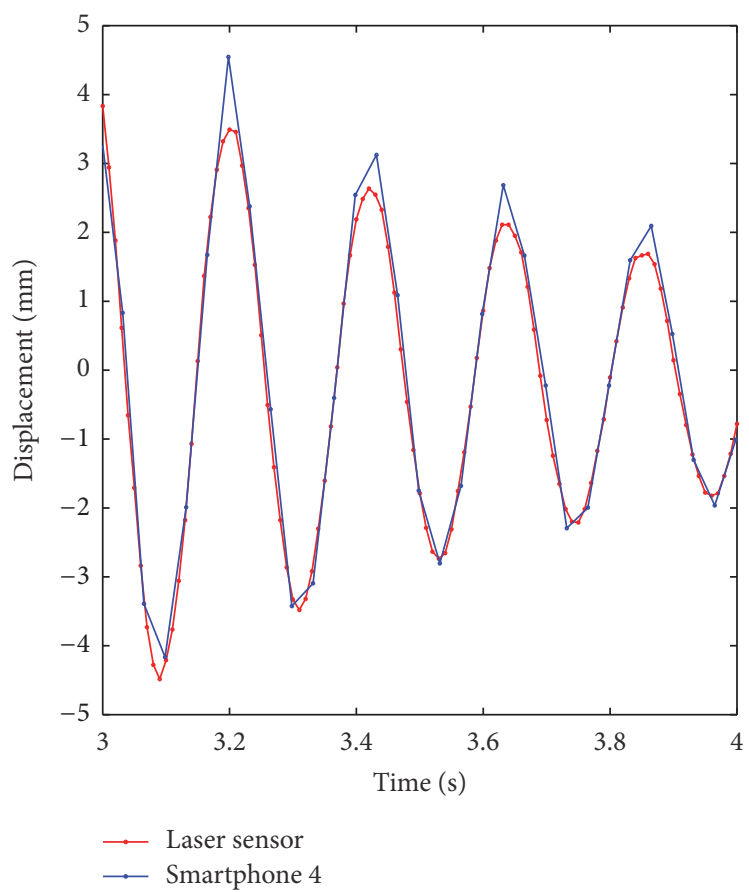

(c) Comparison

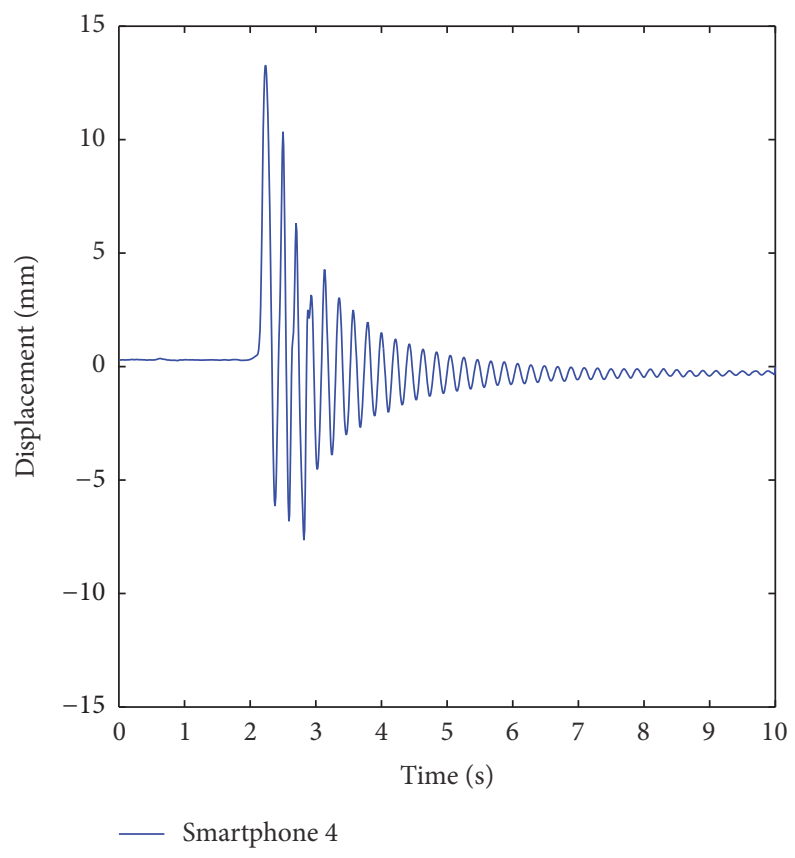

(b) Displacement time history (smartphone)

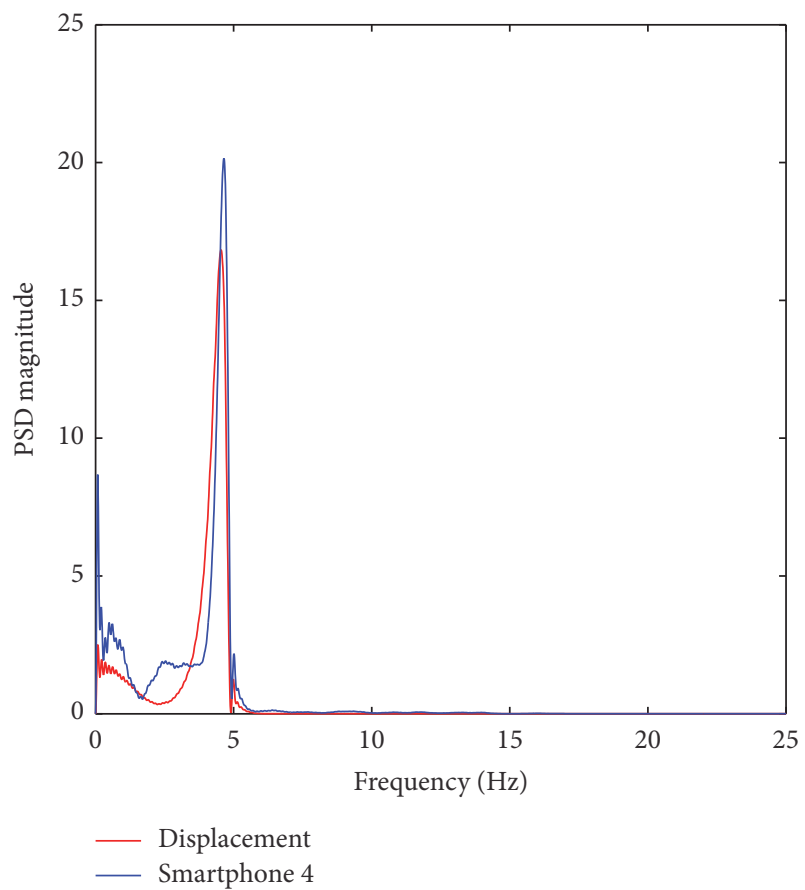

(d) Corresponding PSD

FIGURE 19: Displacement measurement.

with a maximum error of $2.63 \%$. The tests demonstrated that it is possible to extract the dynamic characteristics of the bridge from the various kinds of vibration responses using smartphone and verified the feasibility, accuracy, and reliability of bridge health monitoring method using smartphones.

Based on these preliminary efforts, we are exploring the comprehensive and rapid postevent damage assessment application for bridges using smartphones.

\section{Competing Interests}

The authors declare that there is no conflict of interests regarding the publication of this paper.

\section{Acknowledgments}

Thanks are given to the financial support of the National Natural Science Foundation of China $(51278085,51221961)$. 


\section{References}

[1] J. Ou and H. Li, "Structural health monitoring in mainland China: review and future trends," Structural Health Monitoring, vol. 9, no. 3, pp. 219-231, 2010.

[2] C. R. Farrar and K. Worden, "An introduction to structural health monitoring," Philosophical Transactions of the Royal Society A: Mathematical, Physical and Engineering Sciences, vol. 365, no. 1851, pp. 303-315, 2007.

[3] H. Sohn, C. R. Farrar, F. M. Hemez et al., "A review of structural health monitoring literature: 1996-2001," Los Alamos National Laboratory Report LA-13976-MS, 2004.

[4] H. Wenzel, Health Monitoring of Bridges, John Wiley \& Sons, New York, NY, USA, 2009.

[5] J. M. Ko and Y. Q. Ni, "Technology developments in structural health monitoring of large-scale bridges," Engineering Structures, vol. 27, no. 12, pp. 1715-1725, 2005.

[6] J. M. W. Brownjohn, "Structural health monitoring of civil infrastructure," Philosophical Transactions of the Royal Society A: Mathematical, Physical and Engineering Sciences, vol. 365, no. 1851, pp. 589-622, 2007.

[7] H. Kobayashi, S. Unjoh, and T. Kanou, "Development of an earthquake damage evaluation method for bridge structures using acceleration sensors," Structural Engineering/Earthquake Engineering, vol. 25, no. 1, pp. 25s-32s, 2008.

[8] Y. Yu, X. Zhao, and J. Ou, "A new idea: mobile structural health monitoring using smart phones," in Proceedings of the $3 \mathrm{rd}$ International Conference on Intelligent Control and Information Processing (ICICIP '12), pp. 714-716, IEEE, Dalian, China, July 2012.

[9] G. Morgenthal and H. Höpfner, "The application of smartphones to measuring transient structural displacements," Journal of Civil Structural Health Monitoring, vol. 2, no. 3-4, pp. 149161, 2012.

[10] J. Reilly, S. Dashti, M. Ervasti, J. D. Bray, S. D. Glaser, and A. M. Bayen, "Mobile phones as seismologic sensors: automating data extraction for the ishake system," IEEE Transactions on Automation Science and Engineering, vol. 10, no. 2, pp. 242-251, 2013.

[11] A. Sharma and D. Gupta, "Smartphone as a real-time and participatory data collection tool for civil engineers," International Journal of Modern Computer Science (IJMCS), vol. 2, no. 5, pp. 22-27, 2014.

[12] G. P. Cimellaro, G. Scura, C. S. Renschler, A. M. Reinhorn, and H. U. Kim, "Rapid building damage assessment system using mobile phone technology," Earthquake Engineering and Engineering Vibration, vol. 13, no. 3, pp. 519-533, 2014.

[13] R. Han, X. Zhao, Y. Yu, and J. Ou, "Design and initial validation of mobile-structural health monitoring system based on smart phone," in Proceedings of the 5th Asia-Pacific Workshop on Structural Health Monitoring Conference (AWPSHM '14), Shenzhen, China, 2014.

[14] Y. Yu, X. Zhao, R. Han, and J. Ou, "Design and initial validation of external sensors board of smart phones for mobile structural health monitoring system," in Proceedings of the 7th International Conference on Structural Health Monitoring of Intelligent Infrastructure (SHMII '15), Torino, Italy, 2015.

[15] M. Feng, Y. Fukuda, M. Mizuta, and E. Ozer, "Citizen sensors for SHM: use of accelerometer data from smartphones," Sensors, vol. 15, no. 2, pp. 2980-2998, 2015.
[16] E. Ozer, M. Q. Feng, and D. Feng, "Citizen sensors for SHM: towards a crowdsourcing platform," Sensors, vol. 15, no. 6, pp. 14591-14614, 2015.

[17] H. Tan and J. Chen, "Experiment verification of mobile phones for vibration measurement," in Proceedings of the 7th International Conference on Structural Health Monitoring of Intelligent Infrastructure, Torino, Italy, 2015.

[18] X. Zhao, H. Liu, Y. Yu et al., "Convenient displacement monitoring technique using smartphone," Vibroengineering Procedia, vol. 5, pp. 579-584, 2015.

[19] R. Han, X. Zhao, and Y. Yu, "Convenient posture monitoring on girder hoisting of Dalian Xinghaiwan cross-sea bridge based on smart phone," in Proceedings of the 7th International Conference on Structural Health Monitoring of Intelligent Infrastructure, Torino, Italy, 2015.

[20] X. Zhao, Y. Yu, and M. Li, "Research on Cloud-SHM and its applications," in Proceedings of the 7th International Conference on Structural Health Monitoring of Intelligent Infrastructure, Torino, Italy, 2015.

[21] D. Peng, X. Zhao, Q. Zhao, and Y. Yu, "Smartphone based public participant emergency rescue information platform for earthquake zone-'E-Explorer"' Vibroengineering Procedia, vol. 5, pp. 436-439, 2015.

[22] X. Zhao, "Orion-CC”, https://itunes.apple.com/cn/app/orion$\mathrm{cc} / \mathrm{id} 951253417$ ? $\mathrm{mt}=8$.

[23] X. Zhao, “D-Viewer," https://itunes.apple.com/cn/app/d-view$\mathrm{er} / \mathrm{id} 1006583231$ ? $\mathrm{mt}=8$.

[24] B. Zhang, H. Wan, and C. Mao, "Study on displacement sensor based on difference operation spot center location algorithm," Chinese Journal of Sensors and Actuators, vol. 24, no. 2, pp. 215219, 2011.

[25] Z. Fang and J.-Q. Wang, "Practical formula for cable tension estimation by vibration method," Journal of Bridge Engineering, vol. 17, no. 1, pp. 161-164, 2012.

[26] “iPhone6," http://www.apple.com/iphone-6/specs/.

[27] "BOSCH BMA280," https://www.bosch-sensortec.com/bst/ products/all_products/bma280/.

[28] “InvenSenseMPU-6500," http://www.invensense.com/products/motion-tracking/6-axis/mpu-6500/. 

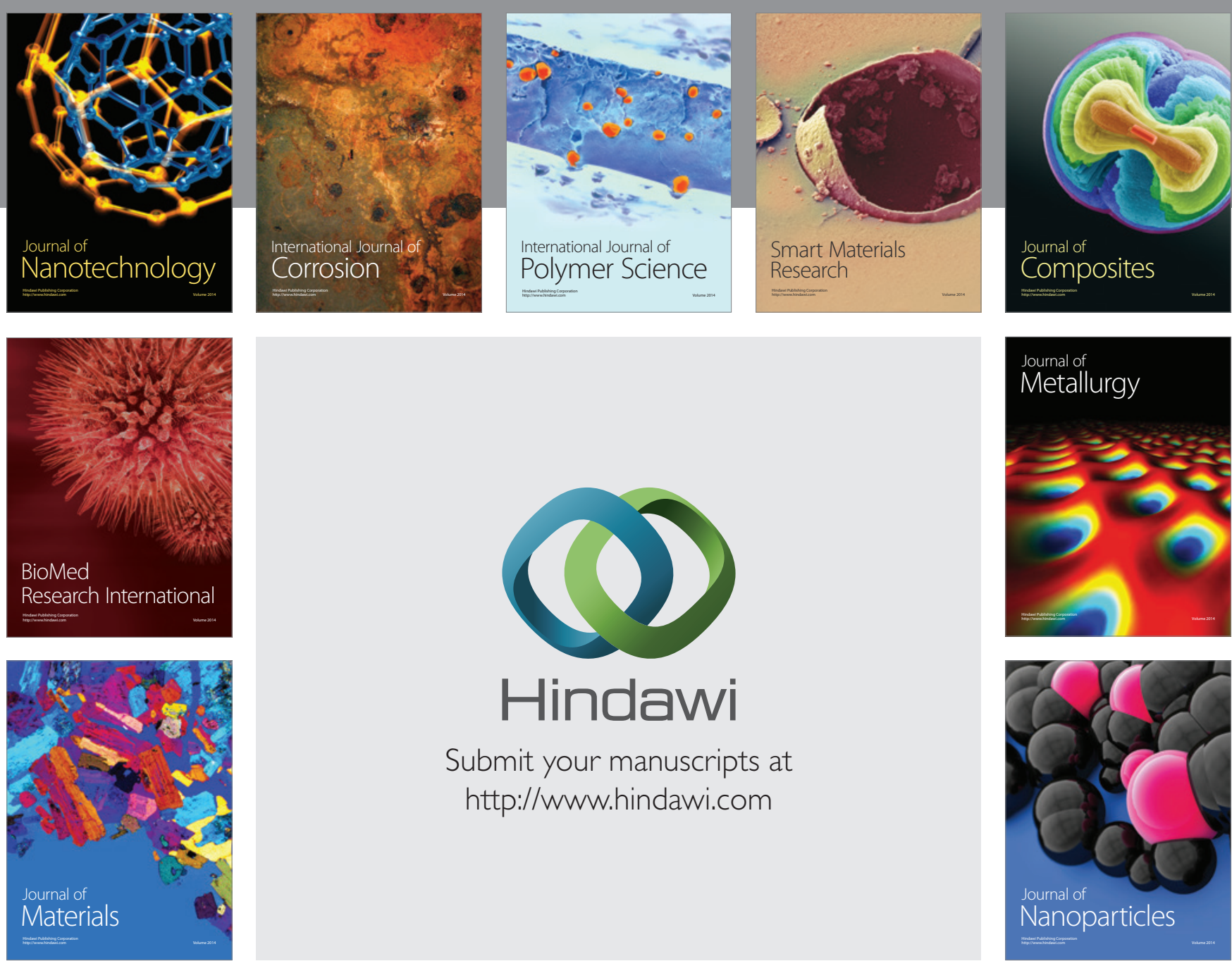

\section{Hindawi}

Submit your manuscripts at

http://www.hindawi.com

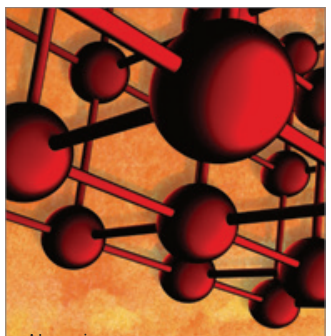

Materials Science and Engineering
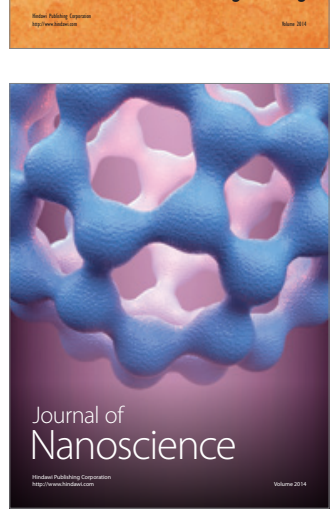
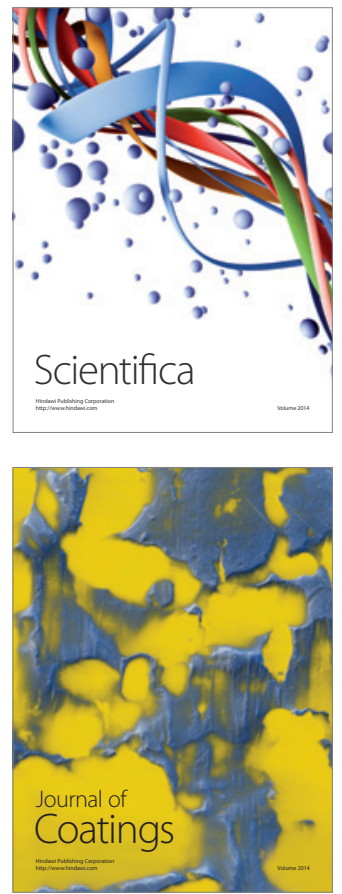
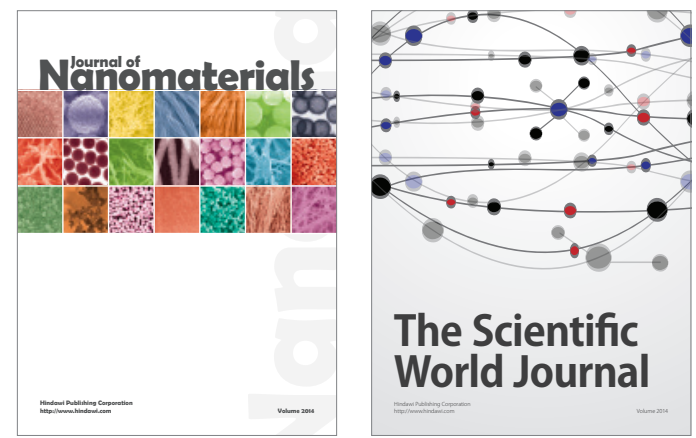

The Scientific World Journal
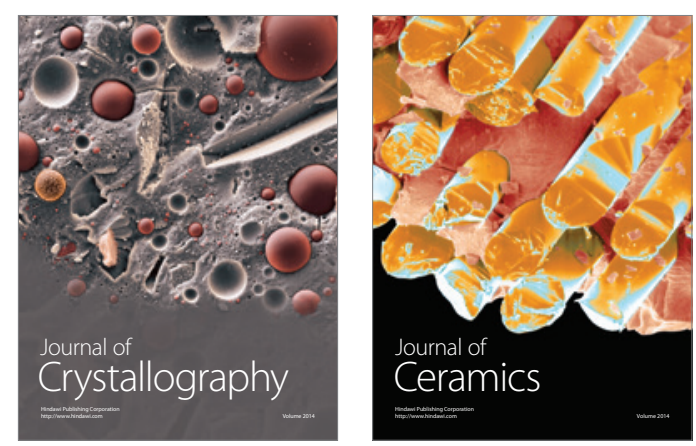
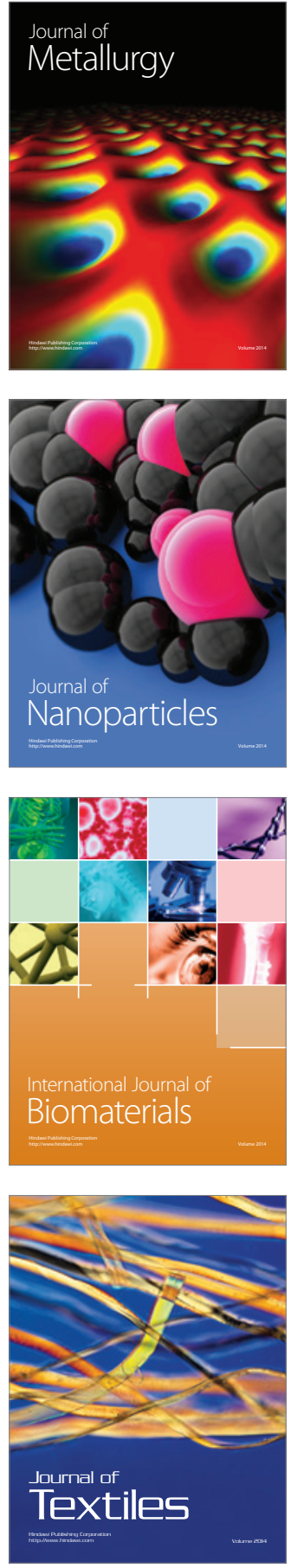